\title{
Enrichment at Vapour-Liquid Interfaces of Mixtures: Establishing a Link between Nanoscopic and Macroscopic Properties
}

\author{
Simon Stephan and Hans Hasse* \\ Laboratory of Engineering Thermodynamics (LTD), TU Kaiserslautern, 67663 Kaiserslautern, Germany
}

\author{
ARTICLE HISTORY \\ Compiled Friday $3^{\text {rd }}$ July, 2020
}

\begin{abstract}
Component density profiles at vapour-liquid interfaces of mixtures can exhibit a non-monotonic behaviour with a maximum that can be many times larger than the densities in the bulk phases. This is called enrichment and is usually only observed for low-boiling components. The enrichment is a nanoscopic property which can presently not be measured experimentally - in contrast to the classical Gibbs adsorption. The available information on the enrichment stems from molecular simulations, density gradient theory, or density functional theory. The enrichment is highly interesting as it is suspected to influence the mass transfer across interfaces. In the present work, we review the literature data and the existing knowledge on this phenomenon and propose an empirical model to establish a link between the nanoscopic enrichment and macroscopic properties - namely vapour-liquid equilibrium data. The model parameters were determined from a fit to a dataset on the enrichment in about 100 binary Lennard-Jones model mixtures that exhibit different types of phase behaviour, which has recently become available. The model is then tested on the entire set of enrichment data that is available in the literature, which includes also mixtures containing nonspherical, polar, and H-bonding components. The model predicts the enrichment data from the literature (2,000 data points) with an AAD of about $16 \%$, which is below the uncertainty of the enrichment data. This establishes a direct link between measurable macroscopic properties and the nanoscopic enrichment and enables predictions of the enrichment at vapour-liquid interfaces from macroscopic data alone.
\end{abstract}

\section{KEYWORDS}

Enrichment, vapour-liquid interface, molecular simulations, density gradient theory 


\section{Outline}

1. Introduction

2. Nanoscopic Interfacial Properties: Enrichment and Relative Adsorption

3. Review of Data on the Enrichment at Vapour-Liquid Interfaces and Database

4. Enrichment Model and Parametrisation

4.1 Dataset used for the Parametrisation

4.2 Empirical Enrichment Model

5. Testing the Model Predictions

6. Conclusions and Future Work

\section{Introduction}

Vapour-liquid interfaces of mixtures are important in many fields, such as chemical engineering, environmental science, and energy technology. In macroscopic models, the interface is generally considered to be a two-dimensional boundary where the density exhibits a discontinuous change. On the nanoscale, however, the density changes continuously from its liquid bulk to its gas bulk value in the interfacial region. While experimental information can be obtained on the orientation of molecules and on dielectric properties at the interface [1-6], there are currently no experimental methods available to study the profiles of thermodynamic properties like the density and pressure in the interfacial region, which is mainly due to the fluctuations of the interface. However, such profiles can be predicted by theoretical methods based on molecular thermodynamics, namely molecular simulations, density gradient theory (DGT), and density functional theory (DFT).

While the total number density of mixtures changes monotonously at vapour-liquid interfaces this does not necessarily hold for the individual component densities. The density of the low-boiling component is often found to exhibit a maximum at the interface. We refer to this phenomenon as enrichment. This interesting phenomenon has been reported since the early days of theoretical studies of interfacial properties of mixtures [7-13]. Its presence has been confirmed by different independent theoretical methods for many systems [13-27]. The enrichment has caused much attention in the past decades, e.g. Refs. [7, 9, 12, 28-31], not least because it is believed to have an influence on the mass transfer through the interface $[10,12,25$, 26, 32-36] and might therefore be important for many technical applications like fluid separation processes.

Strong enrichment at vapour-liquid interfaces is usually found in systems in which one of the components is supercritical. Furthermore, strong enrichment is usually found at low temperatures and low concentrations of the low-boiling component. These results indicate that mixtures that are typical for absorption processes for fluid separation usually show an important enrichment, whereas the enrichment is 
less important for mixtures that are typically separated by distillation. It is well-known that absorption and distillation processes are generally designed differently, even though the columns that are used in both processes are similar: while rate-based models are preferred for absorption, equilibrium stage models are the standard choice for distillation. These differences might be related to the presence of the enrichment in the absorption systems. Rate-based models do not account explicitly for the influence of the enrichment, but they can do this indirectly as a result of their parametrisation.

Predictions of the enrichment with theoretical methods is a complex task: for molecular simulations, suitable force fields must be available and time-consuming direct simulations of the interface must be carried out; similarly DGT requires a suitable equation of state (EOS) together with a parametrisation of the gradient term, and a DGT-code, which is presently not standard in process simulators. Hence, a reliable short-cut method for the estimation of the enrichment would be desirable.

In the present work, we review the available literature data on component density profiles at vapourliquid interfaces, give an account on central points of the existing knowledge on the enrichment, and propose a simple model for the prediction of the enrichment from vapour-liquid equilibrium (VLE) properties. The literature data is evaluated and the available data on the enrichment is collected in a database that is provided in an electronic form in the Supplementary Material. A comprehensive dataset on the enrichment at vapour-liquid interfaces in simple model mixtures $[14,25,27]$ was used for the training of the model, which is then tested on all available enrichment data. The predictions from that model are practically within the uncertainties of the theory-based computations, which provides a short-cut method to reliably estimate the enrichment from macroscopic properties instead of using complex theoretical methods such as molecular simulations or DGT.

The present work is limited to the investigation of vapour-liquid interfaces of binary mixtures of molecular fluids. Related work on electrolyte solutions and ionic liquids [2,37-43], on the behaviour of surfactants at interfaces [44-49], as well as on the enrichment of components at liquid-liquid interfaces [27, 31, 33, 50-54] is not covered. Since theoretical methods for the prediction of component density profiles, namely molecular simulation, DGT, and DFT have been reviewed in detail elsewhere [55-59] their description is not subject of the present paper.

This paper is organised as follows: As different terminologies are used in the literature, first, the studied properties are defined. Then, the literature data on the enrichment of components at vapour-liquid interfaces in binary mixtures is reviewed and discussed. Subsequently, the development and parametrisation of the empirical model for the prediction of the enrichment from macroscopic properties is presented, including a brief discussion of the choice of descriptors. Then, the empirical model is tested on available enrichment data from the literature. Finally, conclusions are drawn and options for future developments in the field are discussed. 


\section{Nanoscopic Interfacial Properties: Enrichment and Relative Adsorption}

To quantify the non-monotonicity of component density profiles, Becker et al. [17] introduced the enrichment $E_{i}$ of a component $i$ at the interface as

$$
E_{i}=\frac{\max \left(\rho_{i}(z)\right)}{\max \left(\rho_{i}^{\prime}, \rho_{i}^{\prime \prime}\right)}
$$

where $\rho_{i}(z)$ are the component number density profiles across the vapour-liquid interface, $z$ indicates the direction normal to a (nanoscopically) planar interface, and $\rho_{i}^{\prime}$ and $\rho_{i}^{\prime \prime}$ indicate the saturated liquid and vapour densities of component $i$, respectively.

The focus of the present work is on the investigation of the non-monotonicity of component density profiles $\rho_{i}(z)$ at vapour-liquid interfaces of mixtures. Two similar effects are not covered: the oscillatory layering structure at fluid interfaces (a structural effect which is also observed for pure components) [60-63] and the non-monotonic behaviour of the total density which is sometimes observed at liquid-liquid and fluidfluid interfaces $[27,34,63-68]$. The amplitude of the enrichment, i.e. the peak height of component density profiles $\rho_{i}(z)$ at vapour-liquid interfaces, is usually significantly larger than the amplitude of the peaks in the aforementioned phenomena. But, it should be noted that the enrichment and the two aforementioned phenomena may be present simultaneously in some situations, cf. Ref. [69].

In the present work, vapour-liquid interfaces of binary mixtures are discussed; the low-boiling component is denoted by '2' and the high-boiling component by '1'. By definition, cf. Eq. (1), the enrichment $E_{i}$ has values equal to or larger than unity. In binary mixtures, an enrichment $E_{i}>1$ is only observed for the lowboiling component 2. At least, no contrary evidence has been reported yet to the best of our knowledge. In the case of multicomponent mixtures, a simultaneous enrichment has been reported for several low-boiling components $[16,70-75]$.

Fig. 1 shows snapshots of two exemplary mixtures with the corresponding density profiles of component 2: the mixture that is depicted in the top panel of Fig. 1 exhibits an enrichment of the low-boiling component at the vapour-liquid interface, while no enrichment is observed for the mixture shown in the lower panel.

Besides the enrichment $E_{2}$, also the relative adsorption $\Gamma_{2}^{(1)}$ of a low-boiling component 2 with respect to component 1 (blue shaded area in Fig. 1) characterises the surface excess. $\Gamma_{2}^{(1)}$ quantifies the number of adsorbed molecules per unit area at the interface, as described in more detail in the Appendix. The relative adsorption $\Gamma_{2}^{(1)}$ can be calculated from macroscopic properties or the nanoscopic density profiles $\rho_{i}(z)[76]$. The relative adsorption $\Gamma_{2}^{(1)}$ can be determined experimentally - at least indirectly [57, 77]: The Gibbs adsorption equation provides a direct link between macroscopic properties and the relative adsorption, cf. Appendix. The relative adsorption obtained from that macroscopic route and from its nanoscopic 


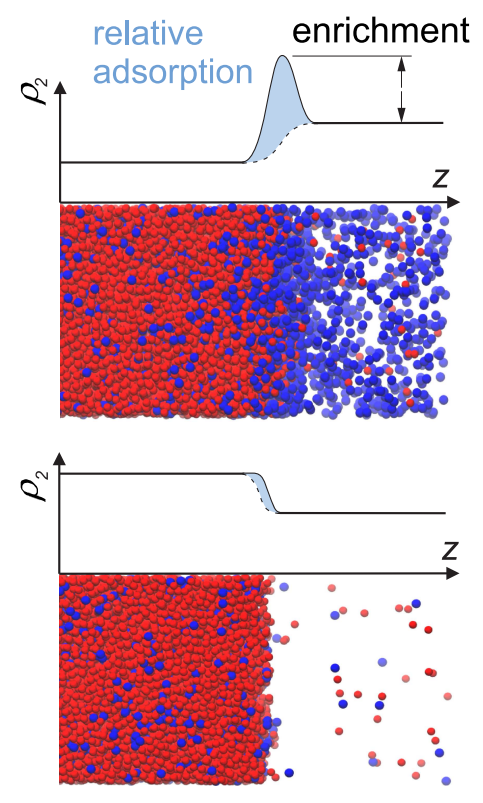

Figure 1. Schemes of vapour-liquid interfaces of two exemplary mixtures. The particles of the high-boiling component 1 are shown in red, those of the low-boiling component 2 in blue. Top: component 2 exhibits an enrichment $E_{2}>1$ and relative adsorption $\Gamma_{2}^{(1)}>0$; Bottom: component 2 exhibits no enrichment $E_{2}=1$ but a relative adsorption $\Gamma_{2}^{(1)}>0$. The scheme is based on simulation screen shots from the simulation data from earlier work of our group [27]. For the visualization, the distance of the particles from the image plane is indicated by their transparency.

definition, i.e. the integral under the density profiles (cf. Fig. 1), are usually found to be in good agreement $[12,15,17,18,20,23,78-86]$. This indicates that the underlying density profiles (including the contribution of the enrichment to $\Gamma_{2}^{(1)}$, cf. Fig. 1 - top) predicted from theoretical methods are in agreement with the reality.

Comparing the enrichment $E_{2}$ and the relative adsorption $\Gamma_{2}^{(1)}$, it should be noted that only the latter is thermodynamically rigorously defined, in a sense that it can be derived from thermodynamic potentials (see Appendix), whereas the enrichment was introduced as a simple geometric measure to characterise the surface excess regarding the non-monotonicity of the density profiles. $E_{2}$ is a dimensionless property, whereas $\Gamma_{2}^{(1)}$ has the dimension number of particles per unit area.

Even though both $\Gamma_{2}^{(1)}$ and $E_{2}$ characterise the surface excess of the low-boiling component, both properties show important differences. For example for systems solvent $1+$ supercritical gas 2 [15, 17, 25]: Starting at infinite dilution of component 2, the relative adsorption $\Gamma_{2}^{(1)}$ increases with increasing mole fraction of component 2 in the liquid phase $x_{2}^{\prime}$, passes through a maximum and decreases to zero at the critical point of the mixture. The enrichment $E_{2}$ in such mixtures, on the other hand, is highest at infinite dilution of component 2 and decreases monotonously with increasing $x_{2}^{\prime}$.

Furthermore, it is not unusual that mixtures exhibit a positive relative adsorption $\Gamma_{2}^{(1)}>0$ but no enrichment, i.e. $E_{2}=1[25,27]$. Such a case is visualised in Fig. 1 - bottom. Both component density profiles exhibit a monotonic transition across the interface, but the profiles are slightly shifted with regard to one another in $z$-direction, which causes a positive relative adsorption $\Gamma_{2}^{(1)}>0$ - without an enrichment. 
However, an enrichment $E_{2}>1$ usually favours high relative adsorption $\Gamma_{2}^{(1)}>0$, cf. Fig. 1 - top. Hence, both the relative adsorption $\Gamma_{2}^{(1)}$ and the enrichment $E_{2}$ characterise the surface excess and are closely linked, but do not express the same information.

\section{Review of Literature Data on the Enrichment at Vapour-Liquid Interfaces and Database}

There is a large body of studies in the literature (approx. 100 publications) reporting on component density profiles $\rho_{i}(z)$ at vapour-liquid interfaces of binary mixtures, of which Table 1 gives an overview. The density profiles $\rho_{i}(z)$ were obtained from different theoretical methods (molecular simulations, DGT, DFT, or a combination of those). Since data on ternary and multicomponent mixtures have been reported relatively scarcely in the literature $[36,54,70-75,87-93]$, they are not listed in Table 1.

Studies on the prediction of interfacial properties of mixtures by theoretical methods mostly focus on the prediction of the surface tension, but also often report density profiles and the relative adsorption $\Gamma_{2}^{(1)}$. In most cases, a qualitative description and discussion of the observations regarding the monotonicity of the component density profiles $\rho_{i}(z)$ is given in the publications. But those findings are rarely put into relation with other works and to the phase behaviour of the considered mixture.

In most publications on vapour-liquid interfacial properties, cf. Table 1, the density profiles are unfortunately only reported for a small subset of the performed simulations (the surface tension is the main observable of interest). Hence, a large number of primary data remained unpublished in this field. The vast majority of studies (cf. Table 1 ) report the density profiles $\rho_{i}(z)$ only graphically. The enrichment $E_{2}$ according Eq. (1) was rarely computed and reported. For the density profiles, unfortunately no consistent form for plotting the data was established, i.e. sometimes only one of the component density profiles was reported and sometimes all. Electronic data of density profiles was practically never reported.

From the density profiles $\rho_{2}(z)$ reported in the literature, cf. Table 1 , the enrichment $E_{2}$ was calculated in the present work. If, as in most cases, $\rho_{2}(z)$ was only reported graphically in the publication, the data were digitalised [94] and the maximum of the low-boiling component's density profile as well as the larger bulk density were metered from the plots, which introduces a considerable uncertainty. To estimate the uncertainty of this 'measuring' process, the digitalisation and evaluation was repeated five times and the standard deviation was taken as a measure of the uncertainty due to the digitalisation procedure. The average uncertainty of the results for $E_{2}$ is approximately $\delta E_{2}= \pm 0.1$. The digitalised data $E_{2}\left(T, x_{2}^{\prime}, \Delta \rho_{2}\right)$ are reported in an electronic spread sheet in the Supplementary Material, where also more details on the procedure are given.

Studies reporting vapour-liquid interfacial properties focus on a large variety of different systems and applications, such as enhanced oil recovery [18, 20, 23, 95-100], natural gas [19, 22, 101-105], $\mathrm{CO}_{2}$ absorption 
and carbon-capture and storage (CCS) [20, 79, 102, 106-111], refrigerants [112-115], evaporation and nucleation [32, 116], environmental science [117-119], process and chemical engineering $[15,17,26,83,108,120-$ 123], polymers [124, 125], fundamental physics [7, 13, 14, 69, 126, 127], and the development of computational methods and algorithms $[8,21,32,80,92,128-131]$. Hence, they were published in a large variety of different journals. Due to this heterogeneity of applications and motivations, there is no dense citation network present in this field. It was one goal of the present paper to establish the corresponding links.

Density profiles at vapour-liquid interfaces have been investigated for both model fluids [7, 10-14, 24, $25,76,80,132-138]$ (very often the Lennard-Jones fluid) and models of real substances [9, 17-19, 22, 28$30,32,35,75,79,88,106,124,139-141]$. These groups differ mainly in the way the molecular model is used: model fluids are usually used to study the effect of a variation of the molecular parameters on a given observable, whereby a generic information is obtained, whereas models of real substances are used to study properties of a given mixture, which causes the findings to be primarily restricted to that case.

The influence of the molecular parameters on density profiles and other interfacial properties has been studied several times in the literature. Results are available for the influence of the size and energy parameters of the pure components $[10,11,13,14,24,25,27,52,133,136,137,142]$, the cross interactions $[10,11,13,14,24,25,27,133,142]$, and the chain length of the components [18, 32, 98, 102, 132, 143, 144]. Some studies also investigated the influence of associating components $[17,79,106,109]$ on vapour-liquid interfacial properties. Asymmetric mixtures have caused special interest $[9,18,79,98,102,106,108,109,141]$ since a particularly high enrichment is found in such cases.

The most frequently studied systems are $\left(\mathrm{H}_{2} \mathrm{O}+\mathrm{CO}_{2}\right),\left(\mathrm{H}_{2} \mathrm{O}+\right.$ alcohols $)$, as well as $\left(\mathrm{CO}_{2}\right.$ or $\mathrm{N}_{2}+$ alkanes), and Lennard-Jones mixtures (cf. Table 1). The latter were mostly used for systematic studies of the influence of molecular parameters on different interfacial and bulk properties. Also, most of the early simulation studies on interfacial properties [7, 10-13] were performed with Lennard-Jones fluids. Mixtures of simple fluids (argon, neon, krypton, methane etc.) can be modelled reasonably well as Lennard-Jones mixtures. Hence, such data can be considered real substance data or model fluid data. Table 1 reports such data as it is referred to in the respective publication.

Also the influence of the temperature $[13,15,17,27]$ and the composition $[25,26]$ on the interfacial enrichment has been investigated systematically in the literature. Overall it was found that an enrichment is favoured by asymmetric molecular interactions, large differences in the volatility of the pure components (i.e. wide-boiling phase behaviour), low concentrations of the low-boiling components, and low temperatures $[14,17,18,22,25,26,98,106,109,145,146]$. In most cases, starting at infinite dilution of component 2, the enrichment $E_{2}$ was found to decrease monotonically with increasing concentration of the low-boiling component 2 at constant temperature to converge to unity either at a critical point, an azeotropic point, or the high-boiling pure component vapour pressure (depending on the phase behaviour). 
Furthermore, two types of enrichment behaviour have been reported for wide-boiling mixtures [14, 25] depending on the sign of the density difference of component $2 \Delta \rho_{2}=\rho_{2}^{\prime}-\rho_{2}^{\prime \prime}$ : mixtures with $\Delta \rho_{2}>0$ usually yield large enrichment, whereas mixtures with $\Delta \rho_{2}<0$ usually yield small enrichment. For example solvent + nitrogen systems usually yield $\Delta \rho_{2}<0$, which goes in hand with small enrichment, whereas solvent + carbon dioxide or solvent + methane systems usually have $\Delta \rho_{2}>0$, which goes in hand with large enrichment (see Supplementary Material). This differentiation has also been confirmed for different types of Lennard-Jones model mixtures, cf. Ref. [14].

The results for the enrichment obtained from the literature data lie almost exclusively in the range of $1<E_{2}<10$, whereat the vast majority of data lies in the range $1<E_{2}<3$. On the other hand, enrichment data in the range $6<E_{2}<10$ is rare. Fig. 2 shows a corresponding histogram.

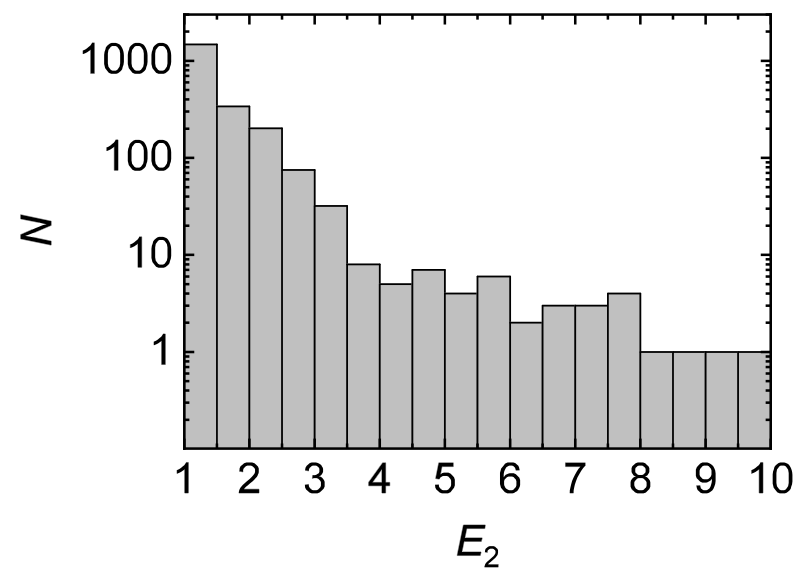

Figure 2. Histogram of the data on the enrichment $E_{2}$ obtained from the literature, cf. Table $1 . N$ is the number of data points in the indicated $E_{2}$ interval. A logarithmic scale is used for $N$.

Particularly large enrichment is often observed for mixtures that exhibit a three-phase vapour-liquidliquid-equilibrium (VLLE). The enrichment at (two-phase) vapour-liquid interfaces is related to a wetting transition in the vicinity of a three-phase VLLE [9, 24, 27, 147]: Approaching the VLLE line through a VL two-phase region, the enrichment increases and can be understood as a precursor of the second liquid phase. The enrichment at two-phase vapour-liquid interfaces approaching a VLL three-phase equilibrium line forms a layer that can be considered as a pre-wetting layer. This layer has similar thermodynamic properties as the second liquid phase L2 that appears at the three-phase line [27]. Nevertheless, enrichment $E_{2}>1$ at vapour-liquid interfaces in such systems is also found at thermodynamic conditions (temperature and pressure) far away from the three-phase line. Furthermore, an enrichment has also been reported for many mixtures that do not exhibit a miscibility gap and a VLLE line.

It has been shown that the enrichment exhibits a continuous transition between different types of systems at constant reduced temperature and liquid phase composition. Systematic studies on Lennard-Jones model mixtures $[14,25]$ recently showed that ideal mixtures (in the sense of Raoult's law) and high-boiling azeotropic mixtures exhibit no enrichment, whereas for low-boiling azeotropic mixtures, a significant en- 
richment is found. This is in line with findings for real substance mixtures reported in the literature $[10,25,35,121]$. Furthermore, it was found that the enriching component changes at the azeotropic point [121]. Hence, in each azeotropic branch, the respective low-boiling component exhibits an enrichment at the interface. Nevertheless, enrichment data on azeotropic mixtures is relatively scarce in the literature.

The number of theoretical studies of vapour-liquid interfaces has grown significantly in the last decade, which is probably due to the fact that MD and MC studies of direct VLE simulations, where the vapour and the liquid phase coexist in a simulation box, became computationally readily affordable. Approximately $60 \%$ of the available studies reporting vapour-liquid density profile data of binary mixtures have been published in the last ten years, cf. Table 1.

Most studies on density profiles of vapour-liquid interfaces employ either molecular simulations, i.e. molecular dynamics (MD) or Monte Carlo (MC) simulations using classical force fields [148, 149], or DGT in combination with an EOS. Approximately half of the studies reporting vapour-liquid interfacial density profiles employ density gradient theory (DGT) in combination with an equation of state (EOS). Not all EOS are suited for such studies. An essential prerequisite is that they exhibit only a single van der Waals loop in the two-phase region [150], like cubic EOS or well-behaving SAFT type EOS [151-157]. Density functional theory (DFT) was only applied in few cases, cf. Table 1. In some studies two methods were employed for a given mixture - usually molecular simulations and DGT. Even though, both methods were found to yield good qualitative agreement for the predicted enrichment in practically all cases, significant quantitative differences have been reported many times [15-20, 22-25, 100, 142, 158]. For a given mixture, the reported absolute deviation for the predicted enrichment among different methods mostly lies in the range $\delta E_{2}=0.1 . .1$.

Systematic deviations between molecular simulations and DGT results for the enrichment have been observed several times: for low $E_{2}$ values, molecular simulations typically yield larger enrichment than DGT, whereas for high $E_{2}$ values the DGT results mostly overestimate the MD results for the enrichment $[12,13,15-24,27]$.

Assessing these deviations between the results from molecular simulations and DGT, several sources of error and uncertainties should be considered: leaving aside the problem of the topic of the reproducibility of molecular simulations results [159-163], the underlying pure substance models (EOS and force field) have to be parametrised adequately to yield conformal representations of the VLE, which is not trivial even for the most simple fluids [157]. Furthermore, molecular simulations and DGT have some fundamental differences, e.g. fluctuations are present in the MD density profiles $\rho_{i}(z)$ but not in the corresponding DGT results, cf. Ref. [27] for a detailed discussion.

For the sake of completeness, we briefly point out further interesting aspects related to the enrichment that have been studied in the literature: the peak position and the shape of the peak was found to depend 
on the system and varies with temperature and composition such that the position of the peak can either be on the liquid or the vapour side of the interface $[15,25,27]$ (with respect to the centre of the interface defined as $\left.\rho^{\text {centre }}=0.5\left(\rho^{\prime}+\rho^{\prime \prime}\right)\right)$. Furthermore, the interfacial thickness, the enrichment, and the relative adsorption have been examined simultaneously in some cases as these three properties comprehensively characterise the structure of an interface [15, 27]. Long-range interactions were found to have a minor influence on the enrichment in simple fluid mixtures [142]. Also the pressure tensor across vapour-liquid interfaces of mixtures was measured by many authors $[9,12,109,119,138,145,164]$. The pressure profiles do not exhibit additional oscillations in cases of high $E_{2}$ compared to cases with low $E_{2}$. Moreover, the orientation of enriching species at the interface $[2,41,117,118]$ and the details on the distribution of functional groups at the interface $[3,21,41,42]$ has been investigated. In several cases, a preferential orientation of low-boiling components with respect to the interface was observed [3, 117, 118], compared to a stochastic orientation in the bulk phases. 
Table 1.: Overview of literature data on density profiles at vapour-liquid interfaces of binary mixtures. The vast majority of publications report density profiles only graphically. The density profiles were evaluated in the present work to obtain data on the enrichment $E_{2}$. \# indicates the number of $E_{2}$ data points that could be retrieved from the respective publication. For density profiles from DGT, also the equation of state that was used is specified.

\begin{tabular}{|c|c|c|c|c|}
\hline Authors & Year & $\#$ & Method & System \\
\hline Algaba et al. [83] & 2019 & 12 & $\mathrm{MD}$ & tetrahydrofuran $\mathrm{C}_{4} \mathrm{H}_{8} \mathrm{O}+$ methane $\mathrm{CH}_{4}$ \\
\hline \multirow[t]{2}{*}{$\begin{array}{l}\text { Almadei } \& \text { Telo da } \\
\text { Gama }[165]\end{array}$} & 1989 & 6 & DFT & ethane $\mathrm{C}_{2} \mathrm{H}_{6}+$ krypton $\mathrm{Kr}$ \\
\hline & & & & $\begin{array}{l}\text { ethene } \mathrm{C}_{2} \mathrm{H}_{4}+\text { krypton } \mathrm{Kr} \\
\text { ethane } \mathrm{C}_{2} \mathrm{H}_{6}+\text { ethene } \mathrm{C}_{2} \mathrm{H}_{4}\end{array}$ \\
\hline \multirow[t]{2}{*}{ Aracil et al. $[86]$} & 1989 & 10 & DFT & $\begin{array}{l}\text { carbon disulfide } \mathrm{CS}_{2}+\text { carbon tetrachloride } \\
\mathrm{CCl}_{4}\end{array}$ \\
\hline & & & & carbon disulfide $\mathrm{CS}_{2}+$ dichloromethane $\mathrm{CH}_{2} \mathrm{Cl}_{2}$ \\
\hline $\begin{array}{l}\text { Baidakov \& } \quad \text { Kho- } \\
\text { tienkova [78] }\end{array}$ & 2016 & 6 & $\mathrm{DGT}+\mathrm{VDW}$ & methane $\mathrm{CH}_{4}+$ nitrogen $\mathrm{N}_{2}$ \\
\hline $\begin{array}{l}\text { Baidakov } \\
\text { tsenko }[81]\end{array}$ & 2008 & 1 & MD & argon $\mathrm{Ar}+$ neon $\mathrm{Ne}$ \\
\hline Becker et al. $[17]$ & 2016 & 148 & $\begin{array}{l}\text { MD \& DGT+PC- } \\
\text { SAFT }\end{array}$ & ethanol $\mathrm{C}_{2} \mathrm{H}_{6} \mathrm{O}+$ carbon dioxide $\mathrm{CO}_{2}$ \\
\hline \multirow[t]{2}{*}{ Biscay $[109]$} & 2009 & 2 & $\mathrm{MC}$ & water $\mathrm{H}_{2} \mathrm{O}+$ carbon dioxide $\mathrm{CO}_{2}$ \\
\hline & & & & water $\mathrm{H}_{2} \mathrm{O}+$ hydrogensulfide $\mathrm{H}_{2} \mathrm{~S}$ \\
\hline \multirow[t]{5}{*}{$\begin{array}{l}\text { Breure } \\
{[129]}\end{array}$} & 2012 & 7 & DGT+PC-SAFT & n-heptane $\mathrm{C}_{7} \mathrm{H}_{16}+$ ethylene $\mathrm{C}_{2} \mathrm{H}_{4}$ \\
\hline & & & & n-pentane $\mathrm{C}_{5} \mathrm{H}_{12}+$ methane $\mathrm{CH}_{4}$ \\
\hline & & & & n-heptane $\mathrm{C}_{7} \mathrm{H}_{16}+$ methane $\mathrm{CH}_{4}$ \\
\hline & & & & n-hexane $\mathrm{C}_{6} \mathrm{H}_{14}+$ nitrogen $\mathrm{N}_{2}$ \\
\hline & & & & n-decane $\mathrm{C}_{10} \mathrm{H}_{22}+$ nitrogen $\mathrm{N}_{2}$ \\
\hline Bühl et al. [101] & 2016 & 6 & $\mathrm{DGT}+\mathrm{PC}-\mathrm{SAFT}$ & $\begin{array}{l}\text { sulfur dioxide } \mathrm{SO}_{2}+\text { carbon dioxide } \mathrm{CO}_{2} \\
\text { hydrogen sulfide } \mathrm{H}_{2} \mathrm{~S}+\text { carbon dioxide } \mathrm{CO}_{2}\end{array}$ \\
\hline Cao et al. $[130]$ & 2016 & 1 & $\mathrm{MD}$ & n-decane $\mathrm{C}_{10} \mathrm{H}_{22}+$ carbon dioxide $\mathrm{CO}_{2}$ \\
\hline Carey et al. $[8,28]$ & 1980 & 1 & $\mathrm{DGT}+\mathrm{PR}$ & iso-octane $\mathrm{C}_{8} \mathrm{H}_{18}+$ cyclohexane $\mathrm{C}_{6} \mathrm{H}_{12}$ \\
\hline Chang \& Dang [166] & 2005 & 3 & $\mathrm{MD}$ & water $\mathrm{H}_{2} \mathrm{O}+$ methanol $\mathrm{CH}_{4} \mathrm{O}$ \\
\hline Chen et al. [111] & 2019 & 1 & $\mathrm{MD}$ & water $\mathrm{H}_{2} \mathrm{O}+$ carbon dioxide $\mathrm{CO}_{2}$ \\
\hline Choudhary et al. [23] & 2019 & 12 & $\mathrm{MD} \& \mathrm{DGT}+\mathrm{PR}$ & n-decane $\mathrm{C}_{10} \mathrm{H}_{22}+$ methane $\mathrm{CH}_{4}$ \\
\hline \multirow[t]{2}{*}{ Chow et al. $[107]$} & 2016 & 5 & $\begin{array}{l}\text { DGT+SAFT-VR } \\
\text { Mie }\end{array}$ & $\begin{array}{l}\text { n-decane } \mathrm{C}_{10} \mathrm{H}_{22}+\text { carbon dioxide } \mathrm{CO}_{2} \\
\text { water } \mathrm{H}_{2} \mathrm{O}+\text { carbon dioxide } \mathrm{CO}_{2}\end{array}$ \\
\hline & & & & water $\mathrm{H}_{2} \mathrm{O}+\operatorname{argon} \mathrm{Ar}$ \\
\hline $\begin{array}{l}\text { Cornelisse et al. } \\
{[167,168]}\end{array}$ & 1993 & 7 & $\mathrm{DGT}+\mathrm{PR}$ & n-decan $\mathrm{C}_{10} \mathrm{H}_{22}+$ carbon dioxide $\mathrm{CO}_{2}$ \\
\hline
\end{tabular}




\begin{tabular}{|c|c|c|c|c|}
\hline Authors & Year & $\#$ & Method & System \\
\hline Cornelisse [29] & 1997 & 2 & $\mathrm{DGT}+\mathrm{PR}$ & water $\mathrm{H}_{2} \mathrm{O}+$ ethanol $\mathrm{C}_{2} \mathrm{H}_{6} \mathrm{O}$ \\
\hline & & & & n-hexane $\mathrm{C}_{6} \mathrm{H}_{14}+$ ethanol $\mathrm{C}_{2} \mathrm{H}_{6} \mathrm{O}$ \\
\hline $\begin{array}{l}\text { Eckelsbach et al. } \\
{[164]}\end{array}$ & 2014 & 3 & $\mathrm{MD}$ & acetone $\mathrm{C}_{3} \mathrm{H}_{6} \mathrm{O}+$ nitrogen $\mathrm{N}_{2}$ \\
\hline $\begin{array}{l}\text { Eckelsback \& Vrabec } \\
{[123]}\end{array}$ & 2015 & 2 & $\mathrm{MD}$ & acetone $\mathrm{C}_{3} \mathrm{H}_{6} \mathrm{O}+$ oxygen $\mathrm{O}_{2}$ \\
\hline Enders \& Kahl [35] & 2008 & 4 & $\mathrm{DGT}+\mathrm{SAFT}$ & $\begin{array}{l}\text { acetone } \mathrm{C}_{3} \mathrm{H}_{6} \mathrm{O}+\text { nitrogen } \mathrm{N}_{2} \\
\text { water } \mathrm{H}_{2} \mathrm{O}+\text { ethanol } \mathrm{C}_{2} \mathrm{H}_{6} \mathrm{O} \\
\text { water } \mathrm{H}_{2} \mathrm{O}+\text { butanol } \mathrm{C}_{4} \mathrm{H}_{10} \mathrm{O}\end{array}$ \\
\hline Fabian et al. [118] & 2014 & 4 & $\mathrm{MD}$ & water $\mathrm{H}_{2} \mathrm{O}+$ hydrogen cyanid $\mathrm{HCN}$ \\
\hline Falls et al. $[9]$ & 1983 & 5 & $\mathrm{DGT}+\mathrm{PR}$ & n-decane $\mathrm{C}_{10} \mathrm{H}_{22}+$ carbon dioxide $\mathrm{CO}_{2}$ \\
\hline $\begin{array}{l}\text { Fouad and Vega } \\
{[112]}\end{array}$ & 2017 & 3 & $\mathrm{DGT}+\mathrm{PC}-\mathrm{SAFT}$ & propane $\mathrm{C}_{3} \mathrm{H}_{8}+$ difluoromethane $\mathrm{CH}_{2} \mathrm{~F}_{2}$ \\
\hline \multirow[t]{2}{*}{ Fu et al. $[122]$} & 2011 & 6 & $\mathrm{DGT}+\mathrm{PC}-\mathrm{SAFT}$ & ethanol $\mathrm{C}_{2} \mathrm{H}_{6} \mathrm{O}+$ carbon dioxide $\mathrm{CO}_{2}$ \\
\hline & & & & methanol $\mathrm{CH}_{4} \mathrm{O}+$ carbon dioxide $\mathrm{CO}_{2}$ \\
\hline \multirow[t]{2}{*}{ Garrido et al. $[100]$} & 2017 & 8 & $\begin{array}{l}\text { MD } \\
\text { DGT+SAFT-VR } \\
\text { Mie }\end{array}$ & n-hexane $\mathrm{C}_{6} \mathrm{H}_{14}+$ nitrogen $\mathrm{N}_{2}$ \\
\hline & & & & n-octane $\mathrm{C}_{8} \mathrm{H}_{18}+$ nitrogen $\mathrm{N}_{2}$ \\
\hline Greberg et al. [169] & 2001 & 2 & DGT & krypton $\mathrm{Kr}+$ argon $\mathrm{Ar}$ \\
\hline Ghobadi \& Elliot [21] & 2014 & 4 & $\begin{array}{l}\mathrm{MD} \\
\mathrm{DFT}+\mathrm{SAFT}-\gamma\end{array}$ & heptane $\mathrm{C}_{7} \mathrm{H}_{16}+$ ethane $\mathrm{C}_{2} \mathrm{H}_{6}$ \\
\hline Horváth et al. $[117]$ & 2019 & 7 & MD & water $\mathrm{H}_{2} \mathrm{O}+$ methylamine $\mathrm{CH}_{3} \mathrm{~N}_{2}$ \\
\hline $\begin{array}{l}\text { Ibarra-Tandi et al. } \\
{[170]}\end{array}$ & 2013 & 1 & MD & Morse fluid + Morse fluid \\
\hline Kahl \& Enders [140] & 2002 & 3 & $\mathrm{DGT}+\mathrm{SAFT}$ & n-hexane $\mathrm{C}_{6} \mathrm{H}_{14}+$ methanol $\mathrm{CH}_{4} \mathrm{O}$ \\
\hline Kahl et al. $[171]$ & 2005 & 1 & DFT & methane $\mathrm{CH}_{4}+$ argon $\mathrm{Ar}$ \\
\hline $\begin{array}{l}\text { Khosharay et al. } \\
{[172]}\end{array}$ & 2014 & 4 & DGT + sPC-SAFT & water $\mathrm{H}_{2} \mathrm{O}+$ carbon dioxide $\mathrm{CO}_{2}$ \\
\hline \multirow[t]{2}{*}{$\begin{array}{l}\text { Khosharay et al. } \\
{[115]}\end{array}$} & 2014 & 2 & $\mathrm{DGT}+\mathrm{PR}$ & $\begin{array}{l}\text { water } \mathrm{H}_{2} \mathrm{O}+\text { hydrogen sulfide } \mathrm{H}_{2} \mathrm{~S} \\
\text { dufluoroethane } \mathrm{C}_{2} \mathrm{H}_{4} \mathrm{~F}_{2}+\text { propane } \mathrm{C}_{3} \mathrm{H}_{8}\end{array}$ \\
\hline & & & & $\begin{array}{l}\text { dufluoroethane } \mathrm{C}_{2} \mathrm{H}_{4} \mathrm{~F}_{2}+\text { pentafluorethan } \\
\mathrm{C}_{2} \mathrm{HF}_{5}\end{array}$ \\
\hline \multirow[t]{2}{*}{$\begin{array}{l}\text { Khosharay } \\
{[173]}\end{array}$} & 2014 & 2 & DGT+CK-SAFT & water $\mathrm{H}_{2} \mathrm{O}+$ carbon dioxide $\mathrm{CO}_{2}$ \\
\hline & & & & water $\mathrm{H}_{2} \mathrm{O}+$ methane $\mathrm{CH}_{4}$ \\
\hline \multirow[t]{2}{*}{$\begin{array}{l}\text { Khosharay } \\
{[105]}\end{array}$} & 2016 & 2 & $\mathrm{DGT}+\mathrm{PR}$ & propane $\mathrm{C}_{3} \mathrm{H}_{8}+$ methane $\mathrm{CH}_{4}$ \\
\hline & & & & heptane $\mathrm{C}_{7} \mathrm{H}_{16}+$ methane $\mathrm{CH}_{4}$ \\
\hline Klink E Gross [32] & 2014 & 5 & $\mathrm{DFT}+\mathrm{PC}-\mathrm{SAFT}$ & methane $\mathrm{CH}_{4}+$ carbon monoxide $\mathrm{CO}$ \\
\hline \multirow[t]{2}{*}{ Koller et al. $[120]$} & 2019 & 4 & $\mathrm{MD}$ & n-hexane $\mathrm{C}_{6} \mathrm{H}_{14}+$ carbon dioxide $\mathrm{CO}_{2}$ \\
\hline & & & & n-decane $\mathrm{C}_{10} \mathrm{H}_{22}+$ carbon dioxide $\mathrm{CO}_{2}$ \\
\hline
\end{tabular}

Continued on next page 


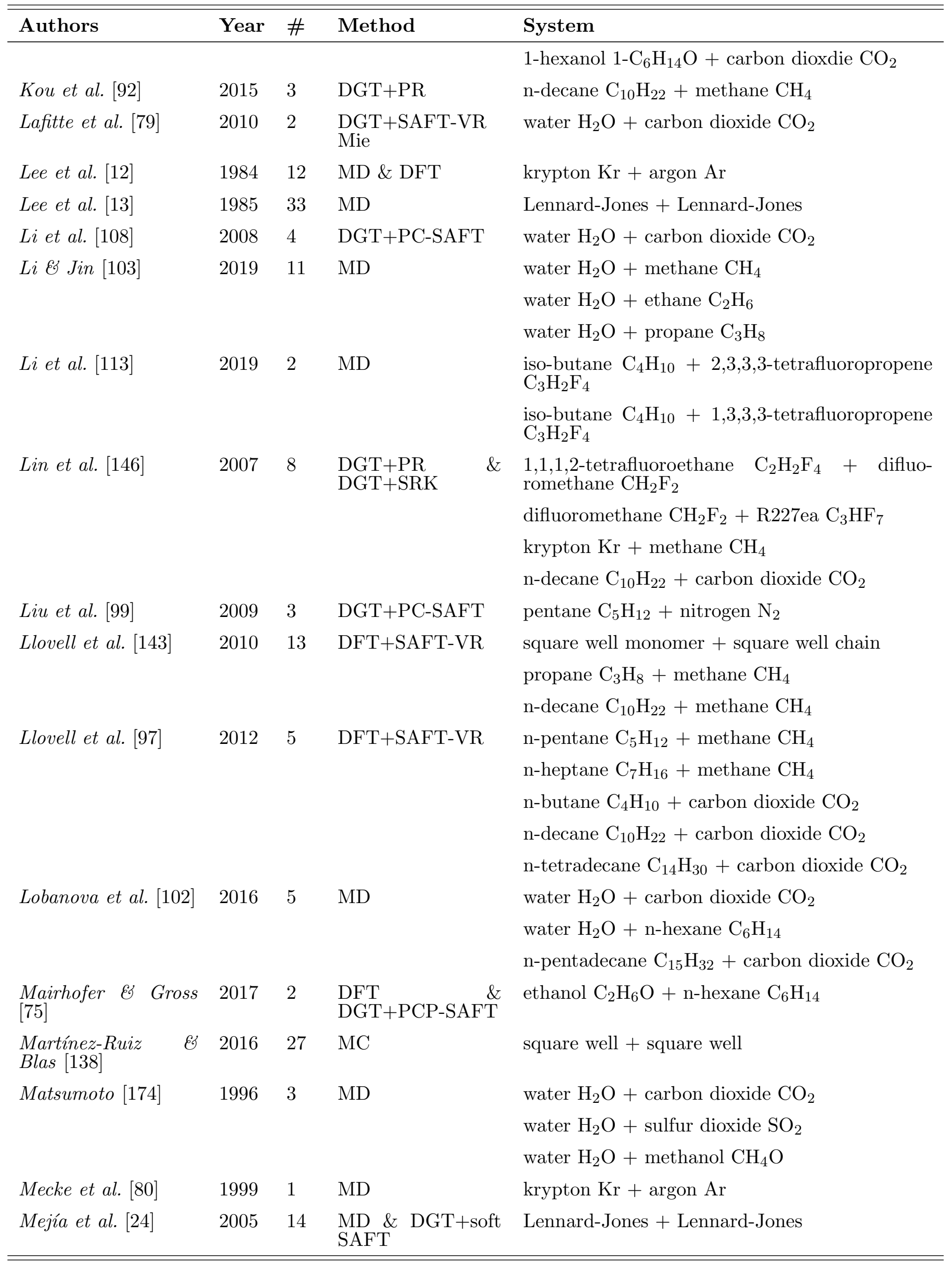

Continued on next page 


\begin{tabular}{|c|c|c|c|c|}
\hline Authors & Year & $\#$ & Method & System \\
\hline Mejía et al. $[20]$ & 2014 & 8 & $\begin{array}{l}\text { MD } \\
\text { DGT+SAFT-VR } \\
\text { Mie }\end{array}$ & n-decane $\mathrm{C}_{10} \mathrm{H}_{22}+$ carbon dioxide $\mathrm{CO}_{2}$ \\
\hline Míguez et al. [19] & 2014 & 9 & $\begin{array}{l}\mathrm{MC} \\
\text { DGT }+\mathrm{SAFT}-\gamma \\
\text { Mie }\end{array}$ & $\begin{array}{l}\text { n-eicosane } \mathrm{C}_{20} \mathrm{H}_{42}+\text { carbon dioxide } \mathrm{CO}_{2} \\
\text { water } \mathrm{H}_{2} \mathrm{O}+\text { carbon dioxide } \mathrm{CO}_{2}\end{array}$ \\
\hline Miqueu et al. [22] & 2011 & 6 & $\begin{array}{l}\mathrm{MC} \& \\
\text { MGT+SAFT-VR } \\
\text { Mie }\end{array}$ & water $\mathrm{H}_{2} \mathrm{O}+$ methane $\mathrm{CH}_{4}$ \\
\hline Miqueu et al. [30] & 2004 & 4 & $\mathrm{DGT}+\mathrm{PR}$ & n-decane $\mathrm{C}_{10} \mathrm{H}_{22}+$ methane $\mathrm{CH}_{4}$ \\
\hline Morita $[175,176]$ & 2003 & 1 & $\mathrm{MD}$ & water $\mathrm{H}_{2} \mathrm{O}+$ methanol $\mathrm{CH}_{4} \mathrm{O}$ \\
\hline Mu et al. $[128]$ & 2017 & 2 & $\mathrm{DGT}+\mathrm{PC}-\mathrm{SAFT}$ & propane $\mathrm{C}_{3} \mathrm{H}_{8}+$ methane $\mathrm{CH}_{4}$ \\
\hline Mucha et al. [119] & 2003 & 3 & $\mathrm{MD}$ & krypton $\mathrm{Kr}+$ argon Ar \\
\hline Müller \& Mejía [18] & 2009 & 18 & $\begin{array}{l}\mathrm{MD} \\
\mathrm{DGT}+\mathrm{SAFT}\end{array}$ & decane $\mathrm{C}_{10} \mathrm{H}_{22}+$ cyclohexane $\mathrm{C}_{6} \mathrm{H}_{12}$ \\
\hline & & & & $\begin{array}{l}\text { n-decane } \mathrm{C}_{10} \mathrm{H}_{22}+\text { carbon dioxide } \mathrm{CO}_{2} \\
\text { n-eicosane } \mathrm{C}_{20} \mathrm{H}_{42}+\text { ethane } \mathrm{C}_{2} \mathrm{H}_{6}\end{array}$ \\
\hline Müller \& Mejía [127] & 2014 & 1 & MD & water $\mathrm{H}_{2} \mathrm{O}+$ carbon dioxide $\mathrm{CO}_{2}$ \\
\hline Naeiji et al. $[104]$ & 2019 & 3 & $\mathrm{MD}$ & water $\mathrm{H}_{2} \mathrm{O}+$ methane $\mathrm{CH}_{4}$ \\
\hline Neyt et al. $[110]$ & 2012 & 4 & $\mathrm{MC}$ & $\begin{array}{l}\text { n-butane } \mathrm{C}_{4} \mathrm{H}_{10}+\text { carbon dioxide } \mathrm{CO}_{2} \\
\text { decane } \mathrm{C}_{10} \mathrm{H}_{22}+\text { carbon dioxide } \mathrm{CO}_{2}\end{array}$ \\
\hline Neyt et al. $[145]$ & 2013 & 2 & MD & $\begin{array}{l}\text { water } \mathrm{H}_{2} \mathrm{O}+\text { methane } \mathrm{CH}_{4} \\
\text { water } \mathrm{H}_{2} \mathrm{O}+\text { nitrogen } \mathrm{N}_{2}\end{array}$ \\
\hline $\begin{array}{l}\text { Niño-Amézquita et } \\
\text { al. }[177]\end{array}$ & 2010 & 4 & $\mathrm{DGT}+\mathrm{PR}$ & n-heptane $\mathrm{C}_{7} \mathrm{H}_{16}+$ carbon dioxide $\mathrm{CO}_{2}$ \\
\hline $\begin{array}{l}\text { Niño-Amézquita et } \\
\text { al. }[106]\end{array}$ & 2012 & 3 & $\mathrm{DGT}+\mathrm{PC}-\mathrm{SAFT}$ & water $\mathrm{H}_{2} \mathrm{O}+$ carbon dioxide $\mathrm{CO}_{2}$ \\
\hline $\begin{array}{l}\text { Niño-Amézquita et } \\
\text { al. }[178]\end{array}$ & 2010 & 4 & $\mathrm{DGT}+\mathrm{PC}-\mathrm{SAFT}$ & n-heptane $\mathrm{C}_{7} \mathrm{H}_{16}+$ methane $\mathrm{CH}_{4}$ \\
\hline $\begin{array}{l}\text { Niño-Amézquita } \\
\text { Enders }[141]\end{array}$ & 2016 & 3 & $\mathrm{DGT}+\mathrm{PC}-\mathrm{SAFT}$ & water $\mathrm{H}_{2} \mathrm{O}+$ methane $\mathrm{CH}_{4}$ \\
\hline Niño-Amézquita [95] & 2013 & 1 & $\mathrm{DGT}+\mathrm{PC}-\mathrm{SAFT}$ & n-heptane $\mathrm{C}_{7} \mathrm{H}_{16}+$ nitrogen $\mathrm{N}_{2}$ \\
\hline Panayiotou [179] & 2003 & 1 & $\mathrm{DGT}+\mathrm{QCHB}$ & 1-propanol $\mathrm{C}_{3} \mathrm{H}_{8} \mathrm{O}+$ n-hexane $\mathrm{C}_{6} \mathrm{H}_{14}$ \\
\hline Pereira et al. $[82]$ & 2016 & 9 & $\mathrm{DGT}+\mathrm{PR}$ & $\begin{array}{l}\text { n-decane } \mathrm{C}_{10} \mathrm{H}_{22}+\text { methane } \mathrm{CH}_{4} \\
\text { n-decane } \mathrm{C}_{10} \mathrm{H}_{22}+\text { carbon dioxide } \mathrm{CO}_{2} \\
\text { n-decane } \mathrm{C}_{10} \mathrm{H}_{22}+\text { nitrogen } \mathrm{N}_{2}\end{array}$ \\
\hline $\begin{array}{l}\text { Poser \& } \quad \text { Sanchez } \\
{[124]}\end{array}$ & 1981 & 1 & $\mathrm{DGT}+\mathrm{LFT}$ & benzene $\mathrm{C}_{6} \mathrm{H}_{6}+$ n-hexane $\mathrm{C}_{6} \mathrm{H}_{14}$ \\
\hline $\begin{array}{l}\text { Protsenko } \\
\text { Baidakov [137] }\end{array}$ & 2016 & 20 & MD & Lennard-Jones + Lennard-Jones \\
\hline Protsenko et al. $[136]$ & 2016 & 6 & $\mathrm{MD}$ & Lennard-Jones + Lennard-Jones \\
\hline Sahimi $\mathcal{E}$ Taylor [98] & 1991 & 2 & $\mathrm{DGT}+\mathrm{PR}$ & n-butane $\mathrm{C}_{4} \mathrm{H}_{10}+$ carbon dioxide $\mathrm{CO}_{2}$ \\
\hline
\end{tabular}

Continued on next page 


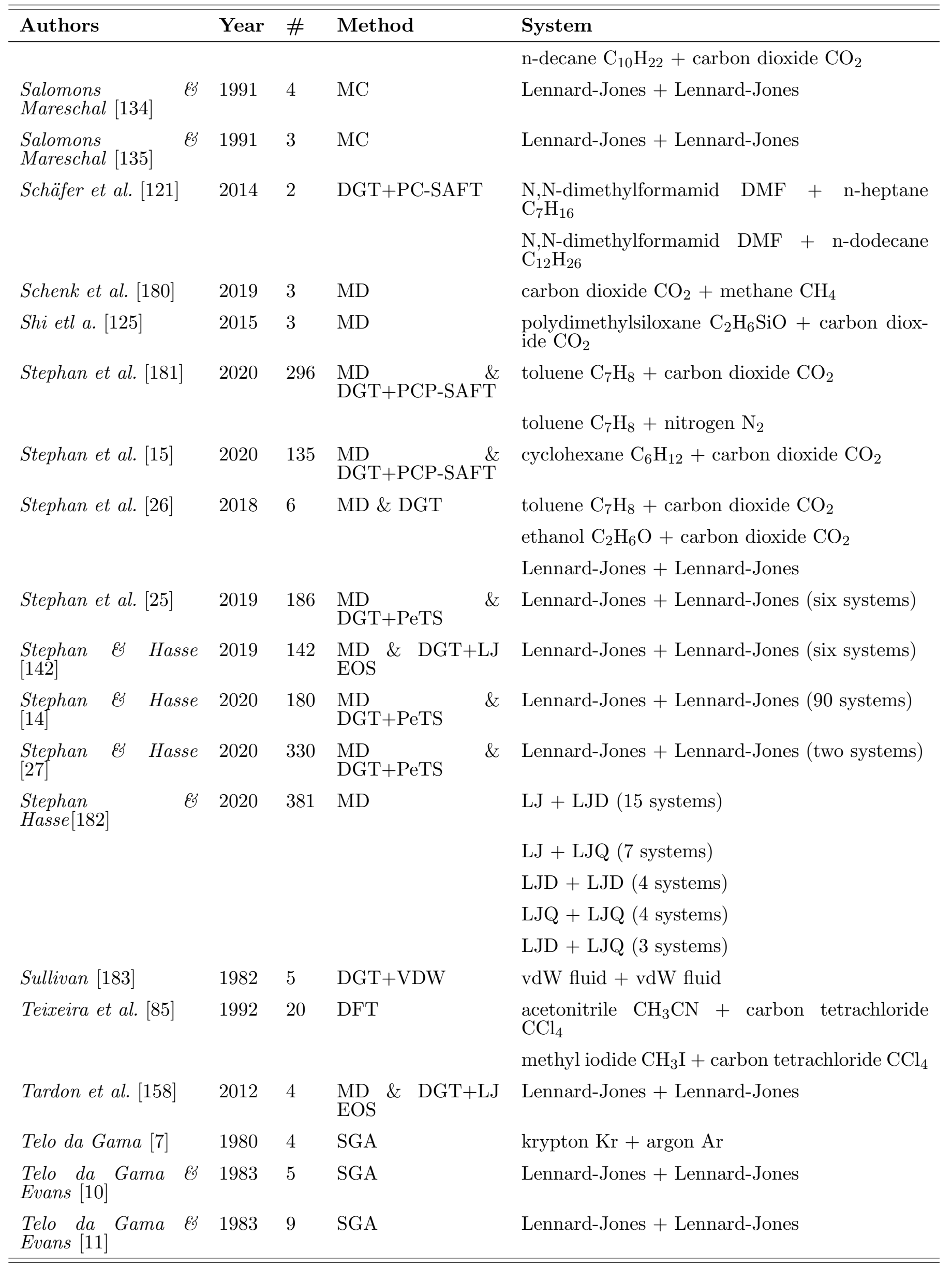

Continued on next page 


\begin{tabular}{|c|c|c|c|c|}
\hline Authors & Year & $\#$ & Method & System \\
\hline Vilaseca et al. $[114]$ & 2010 & 3 & DGT+soft SAFT & dufluoroethane $\mathrm{C}_{2} \mathrm{H}_{4} \mathrm{~F}_{2}+$ propane $\mathrm{C}_{3} \mathrm{H}_{8}$ \\
\hline $\begin{array}{l}\text { Wadewitz } \& \text { Winkel- } \\
\text { mann }[84]\end{array}$ & 1996 & 20 & $\mathrm{DFT}$ & argon $\mathrm{Ar}+$ nitrogen $\mathrm{N}_{2}$ \\
\hline \multirow[t]{2}{*}{ Werth et al. $[16]$} & 2016 & 159 & $\begin{array}{l}\text { MD \& DGT }+ \text { PC- } \\
\text { SAFT }\end{array}$ & $\begin{array}{l}\text { toluene } \mathrm{C}_{7} \mathrm{H}_{8}+\text { n-heptane } \mathrm{C}_{7} \mathrm{H}_{16} \\
\text { toluene } \mathrm{C}_{7} \mathrm{H}_{8}+\text { carbon dioxide } \mathrm{CO}_{2}\end{array}$ \\
\hline & & & & toluene $\mathrm{C}_{7} \mathrm{H}_{8}+$ hydrocloric $\mathrm{HCl}$ \\
\hline Winkelmann [69] & 2001 & 6 & $\mathrm{MD}$ & methane $\mathrm{CH}_{4}+$ argon $\mathrm{Ar}$ \\
\hline Zeng \& Oxtoby [116] & 1991 & 2 & DFT & krypton $\mathrm{Kr}+$ argon Ar \\
\hline
\end{tabular}

Abbreviations:

DFT density functional theory

DGT density gradient theory

EOS equation of state

LFT lattice fluid theory [184]

LJ Lennard-Jones fluid EOS [157, 185-188]

MC Monte Carlo simulation [189, 190]

MD molecular dynamics simulation [189]

PC-SAFT perturbed-chain statistical associating fluid theory EOS [191, 192]

PCP-SAFT perturbed-chain polar statistical associating fluid theory EOS [193-195]

PeTS perturbed truncated shifted EOS [25, 154]

PR Peng-Robinson EOS [196]

QCHB quasi-chemical hydrogen bonding [179]

SAFT statistical associating fluid theory $\operatorname{EOS~}[151,197,198]$

CK-SAFT Chen-Kreglewski SAFT [199, 200]

SAFT-VR Mie EOS SAFT variable range Mie potential EOS [201]

SAFT- $\gamma$ Mie group contribution SAFT-VR Mie EOS version [202]

SAFT VR SAFT variable range EOS [203, 204]

soft SAFT soft SAFT EOS [205, 206]

SRK Soave-Redlich-Kwong EOS [207, 208]

VDW van der Waals EOS

\section{Enrichment Model and Parametrisation}

\subsection{Dataset used for the Parametrisation}

The enrichment database compiled from literature data in the present work (cf. Table 1) was split into two datasets: one for the training of the empirical model and one for the testing. For the training of 
the empirical enrichment model, the comprehensive dataset on binary Lennard-Jones mixtures that was recently published by our group was used $[14,25,27]$. The test-dataset comprises the remaining enrichment data from the literature, cf. Table 1.

The training-dataset comprises a large variety of mixture types and thermodynamic conditions (temperature and liquid phase composition). An overview of the Lennard-Jones mixtures comprised in the training-dataset $[14,25,27]$ is given in Fig. 3, in which the molecular interaction parameters are depicted. For all mixtures, the high-boiling component 1 was the same and both components have the same size parameter $\sigma$ and mass $M$. The mixtures differ in the dispersion energy of the low-boiling component $\varepsilon_{2}$ and the parameter $\xi$ that was used in the modified Berthelot combination rule for describing the cross interactions dispersion energy $\varepsilon_{12}=\xi \sqrt{\varepsilon_{1} \varepsilon_{2}}$. Values of $\xi>1$ indicate an increased cross affinity of the two components and $\xi<1$ a decreased cross affinity. A selection of the resulting isothermal phase diagrams is given in the Supplementary Material.

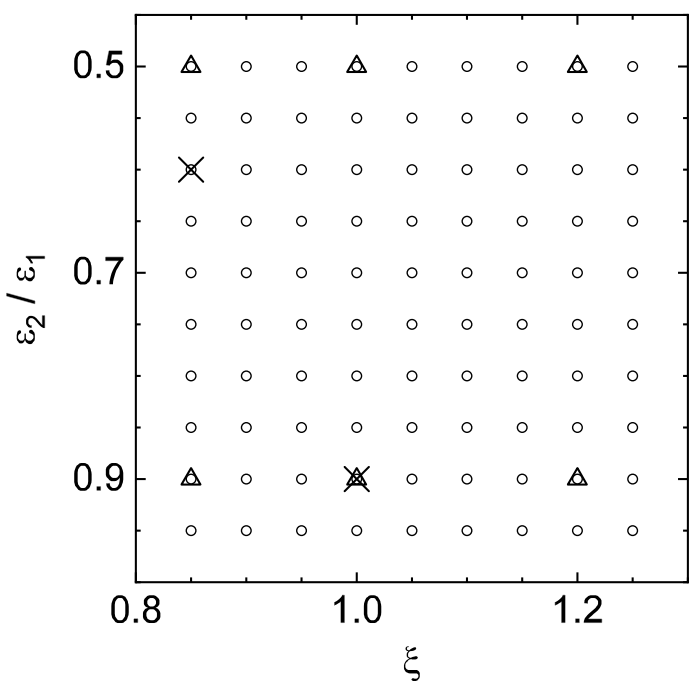

Figure 3. Overview of the binary Lennard-Jones mixtures that were used for the training of the empirical enrichment model. Component 1 was the same for all mixtures. $\varepsilon_{2} / \varepsilon_{1}$ denotes the ratio of the two component's dispersion energy and $\xi$ the cross interaction parameter used in the modified Berthelot combination rule. The particle size $\sigma$ was the same for both components in all cases. Mixtures that are indicated by circles were studied at $x_{2}^{\prime}=0.05 \mathrm{~mol} \mathrm{~mol}^{-1}$ and $T / T_{\mathrm{c}, 1}=0.7[14]$. Mixtures indicated by triangles were studied in the entire composition range at $T / T_{\mathrm{c}, 1}=0.7$ [25]. Mixtures indicated by crosses were studied in the entire composition range and at the temperatures $T / T_{\mathrm{c}, 1}=0.6,0.65,0.7,0.75,0.8[27]$.

Fig. 4 shows the results for the enrichment obtained in these systematic studies [14, 25, 27]. The obtained enrichment is plotted as a function of the liquid phase concentration for the data from Refs. [25, 27] (panels a) - d) and as a function of the partition coefficient for the data from Ref. [14] (panel e).

The training-dataset thereby contains enrichment data of 90 Lennard-Jones systems at only one temperature and liquid phase composition $\left(x_{2}^{\prime}=0.05 \mathrm{~mol} \mathrm{~mol}^{-1}\right)[14]$, six systems at one temperature but the entire composition range [25], and two systems at five temperatures in the entire composition range [27]. All three studies $[14,25,27]$ were carried out using both MD and DGT. For the parametrisation of the enrichment model, only the MD results reported in Refs. [14, 25, 27] were used. The training-dataset covers 

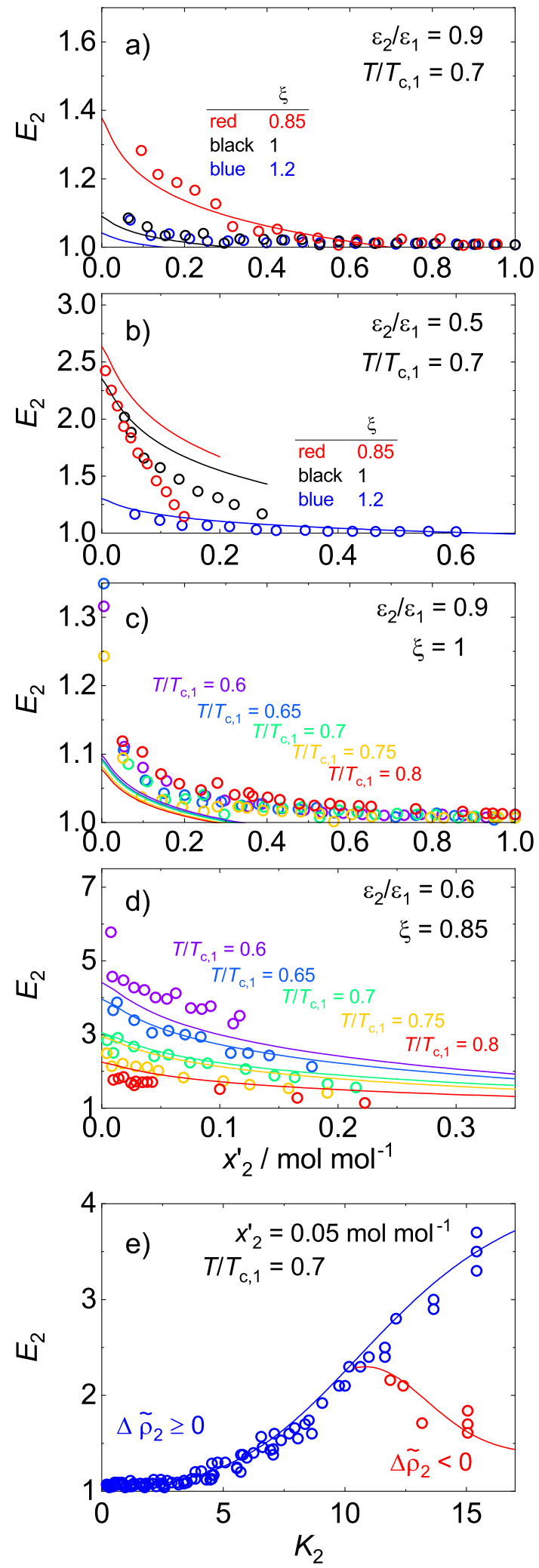

Figure 4. Data on the enrichment of Lennard-Jones mixtures [14, 25, 27] (symbols) that were used for training of the empirical model (lines). The plots (a) and (b) show the enrichment observed in six different Lennard-Jones mixtures at $T / T_{\mathrm{c}, 1}=0.7$ as a function of the liquid phase concentration [25]; (c) and (d) show the enrichment observed in two Lennard-Jones mixtures at five temperatures as a function of the liquid phase concentration [27]; (e) shows the enrichment observed in 90 different Lennard-Jones mixtures at $T / T_{\mathrm{c}, 1}=0.7$ and $x_{2}^{\prime}=0.05 \mathrm{~mol} \mathrm{~mol}^{-1}$ as a function of the partition coefficient $K_{2}=x_{2}^{\prime \prime} / x_{2}^{\prime}$. For all mixtures, both particles have the same size $\sigma_{1}=\sigma_{2}$. 
a wide range of types of phase behaviour. Furthermore, it contains data for a selection of mixtures in the temperature range between the triple point temperature and the critical temperature of the high-boiling component, and the entire concentration range where vapour-liquid equilibria exist in these systems. In total, the training-dataset consists of 338 data points.

For all studied mixtures in the training-dataset, the enrichment $E_{2}$ predicted by MD is largest at infinite

dilution of the low-boiling component and monotonically decreases with increasing $x_{2}^{\prime}$. The enrichment increases with decreasing temperature, cf. Fig. 4 c) and d). The enrichment data at constant temperature and liquid phase concentration $\left(x_{2}^{\prime}=0.05 \mathrm{~mol} \mathrm{~mol}^{-1}\right)$ plotted as a function of the partition coefficient $K_{2}=x_{2}^{\prime \prime} / x_{2}^{\prime}$ (Fig. 4 e) shows an interesting behaviour: All data points collapse to a single curve for values of $K_{2}$ of up to about 12. This is not completely surprising, as in Ref. [14], a general monovariate dependency of the interfacial properties on the internal energy of the liquid phase was found. However, at $K_{2} \approx 12$ a second branch appears in the plot shown in Fig. 4 e). The existence of this second branch is related to the difference of the partial densities of component 2 in the two phases $\Delta \rho_{2}=\rho_{2}^{\prime \prime}-\rho_{2}^{\prime}$. For most systems, the partial density difference $\Delta \rho_{2}$ is positive, i.e. $\rho_{2}$ in the liquid phase is larger than $\rho_{2}$ in the gas phase (which is related to the gas solubility [14]). However, for some systems, the inverse is true, i.e. $\Delta \rho_{2}$ is negative. Both types of systems show large values of $K_{2}$ (the limit is about $K_{2}=12$ ). As shown in Ref. [14], the sign of $\Delta \rho_{2}$ has an important influence on the enrichment. As a consequence, for $K_{2}>12$ a distinction is necessary between systems with $\Delta \rho_{2}>0$ and systems with $\Delta \rho_{2}<0$. The branch found for $\Delta \rho_{2}>0$ in this range of $K_{2}$ is a simple extension of the curve found for lower $K_{2}$, whereas on the other branch $\left(\Delta \rho_{2}<0\right)$, distinctly smaller values of $E_{2}$ are found. While the database is dense for low $K_{2}$, not as many data points are currently available at high $K_{2}$ in the training-dataset, cf. Fig. 4.

\subsection{Empirical Enrichment Model}

As described above, the enrichment $E_{2}$ is considered here as a function of $T$ and $x_{2}^{\prime}$ for a given mixture. The aim was to establish a correlation of $E_{2}$ with readily available macroscopic data on the VLE of the mixture. Correlations in dimensionless variables are preferred. Many options are available for establishing such correlations, and we have tested a number of them in preliminary work. For brevity, we will not describe all these tests and present here only the final result. Our only claim is the usefulness of the correlation, i.e. a good description of the available $E_{2}$ data, not any kind of optimality. A clear indication of the usefulness is the fact that the simple correlation presented here describes the available data on $E_{2}$ in most cases within the uncertainty of the prediction of $E_{2}$ from different methods.

The proposed correlation describes $E_{2}$ as a product of two terms:

$$
E_{2}=\alpha_{0}+f_{a}\left(x_{2}^{\prime}\right) f_{b}(\mathrm{VLE})
$$


and an empirical offset parameter $\alpha_{0}$. The term $f_{a}$ describes the concentration-dependence of $E_{2}$ in a generalised way, the term $f_{b}$ includes the information on the VLE of the considered binary system. Preliminary tests showed that it is not necessary to introduce a universal function of the temperature. The influence of temperature is accounted for in the term $f_{b}$. In the following, empirical parameters employed in the functions $f_{a}$ and $f_{b}$ are labelled as $\alpha_{i}$.

Following the findings shown in Figure $4 \mathrm{e}$ ), the VLE of a mixture is characterised here by the partition coefficient of component 2 , i.e. $K_{2}=x_{2}^{\prime \prime} / x_{2}^{\prime}$. This is convenient, as in all studies of interfacial properties in the literature, the partition coefficient $K_{2}$ can be calculated easily from the available data. Furthermore, the required data on $x_{2}^{\prime \prime}$ and $x_{2}^{\prime}$ are readily available in databases for a large number of mixtures of practical relevance.

The partition coefficient $K_{2}$ depends both on the temperature and composition. For characterising the studied system, the partition coefficient at infinite dilution would have been a convenient choice, since $E_{2}$ was found in all cases to be largest at infinite dilution and monotonically decrease with increasing $x_{2}^{\prime}$ (see discussion above). But since MD simulations can only be carried out at finite concentrations and based on an analysis of the available data and preliminary tests, it was decided to use the partition coefficient at the liquid phase concentration of $x_{2}^{\prime}=0.05 \mathrm{~mol} \mathrm{~mol}^{-1}$ :

$$
K_{2}^{5 \%}=\frac{x_{2}^{\prime \prime}}{x_{2}^{\prime} \equiv 0.05 \mathrm{~mol} \mathrm{~mol}^{-1}} .
$$

For a given mixture, the value of $K_{2}^{5 \%}$ depends on the temperature. This is how the temperature is accounted for in the model.

The dependency of the enrichment on the liquid phase concentration is described by a simple monotonically decaying universal function

$$
f_{a}\left(x_{2}^{\prime}\right)=\alpha_{1}+\ln \left(\frac{1}{x_{2}^{\prime}+\alpha_{2}}\right)-\frac{\alpha_{2}}{x_{2}^{\prime}+\alpha_{2}} .
$$

The function $f_{a}$ has a finite value at $x_{2}^{\prime}=0$ and monotonically decreases with a convex curvature to zero at $x_{2}^{\prime}=0$. The outlined model does not explicitly take three-phase VLLE and critical points into account as termination points for $E_{2}$ isotherms [27]. It would be desirable to consider these end points in the model, but there is presently not enough data to do this in a meaningful way. If more data were available, this is expected to lead to further improvements of the model.

As discussed above, for mixtures with large $K_{2}$, the influence of the density difference of the low-boiling component $\Delta \rho_{2}=\rho_{2}^{\prime}-\rho_{2}^{\prime \prime}$ must be taken into account. This is incorporated in the empirical model by 
defining

$$
f_{b}=\alpha_{3} g_{\mathrm{I}}\left(K_{2}^{5 \%}\right) \delta\left(\Delta \tilde{\rho}_{2}\right)+\alpha_{4} g_{\mathrm{II}}\left(K_{2}^{5 \%}\right)\left(1-\delta\left(\Delta \tilde{\rho}_{2}\right)\right)
$$

where $\delta$ is a smoothed step function taking values between 0 and 1 of the form

$$
\delta\left(\Delta \tilde{\rho}_{2}\right)=\frac{\tanh \left(100 \cdot \Delta \tilde{\rho}_{2}\right)+1}{2} .
$$

In Eq. (6), $\Delta \tilde{\rho}_{2}$ is the reduced density difference with respect to the critical density of the high-boiling component, i.e. $\Delta \tilde{\rho}_{2}=\Delta \rho_{2} / \rho_{\mathrm{c}, 1}$. Hence, also $\Delta \tilde{\rho}_{2}$ is a dimensionless variable. The reduced density difference $\Delta \tilde{\rho}_{2}$ is only used for the decision function $\delta\left(\Delta \tilde{\rho}_{2}\right)$ to navigate between the terms $g_{\mathrm{I}}\left(K_{2}^{5 \%}\right)$ and $g_{\mathrm{II}}\left(K_{2}^{5 \%}\right)$ depending on the sign of $\Delta \tilde{\rho}_{2}$. The value of $\Delta \tilde{\rho}_{2}$ can easily be obtained from saturated density and concentration data, which is readily available for a large number of systems [209, 210].

The two functions for the modelling of the enrichment dependency on the partition coefficient $g_{\mathrm{I}}$ and $g_{\mathrm{II}}$ are defined as

$$
\begin{aligned}
& g_{\mathrm{I}}\left(K_{2}^{5 \%}\right)=\left(\exp \left(\tanh \left(\alpha_{5} \cdot K_{2}^{5 \%}-\alpha_{6}\right)\right)\right)^{\alpha_{7}} \\
& g_{\mathrm{II}}\left(K_{2}^{5 \%}\right)=\alpha_{8}+\exp \left(\alpha_{9} \cdot\left(\frac{K_{2}^{5 \%}-\alpha_{10}}{\alpha_{11}}\right)^{2}\right)
\end{aligned}
$$

The equations (2) - (8) define an empirical enrichment model as a function $E_{2}=E_{2}\left(x_{2}^{\prime}, K_{2}^{5 \%}, \Delta \tilde{\rho}_{2}\right)$. All three variables are dimensionless macroscopic VLE properties that are easily accessible by experiment and are available in data bases for a large number of systems $[209,210]$. The values for $K_{2}^{5 \%}$ and $\Delta \tilde{\rho}_{2}$ can be determined conveniently for both the training-dataset and the test-dataset. For the training-dataset, all required numeric values were reported in the respective publications. The determination of $K_{2}^{5 \%}$ and $\Delta \tilde{\rho}_{2}$ for the test-dataset is discussed in the next section.

The empirical enrichment model has 12 adjustable parameters $\alpha_{i}$ with $i=0$ to 11 , which were fitted to the training-dataset, i.e. the MD Lennard-Jones mixture data from Refs. [14, 25, 27]. The parametrisation was carried out by minimising the absolute average deviation

$$
\mathrm{AAD}_{E_{2}}=1 / N \sum_{j=1}^{N} \frac{\left|\Delta E_{2, j}\right|}{E_{2, j}^{\mathrm{ref}}},
$$

where $N$ is the number of enrichment data points in the training-dataset, $E_{2, j}^{\text {ref }}$ is the reference enrichment from the training-dataset $[14,25,27]$, and $\Delta E_{2}$ is the absolute deviation between the reference value and 
the value predicted by the empirical enrichment model $\Delta E_{2, j}=E_{2, j}^{\text {ref }}-E_{2, j}^{\text {model }}$. Table 2 reports the obtained parameter values for $\alpha_{i}$.

Table 2. Parameters of the empirical enrichment model Eq. (2).

\begin{tabular}{cc|cc}
\hline \hline$i$ & $\alpha_{i}$ & $i$ & $\alpha_{i}$ \\
\hline 0 & 0.9594 & 6 & 0.5521 \\
1 & 0.0199 & 7 & 2.7099 \\
2 & 0.01 & 8 & 0.4706 \\
3 & 0.0811 & 9 & -0.05 \\
4 & 0.3414 & 10 & 10.85 \\
5 & 0.1345 & 11 & 0.8 \\
\hline \hline
\end{tabular}

The model described above is empirical. Experience tells us that the limits of applicability of such models are related to the range of states covered by the training-dataset. In our case the considered VLE regions ended always in the boiling point of the high-boiling component 1 , i.e. infinite dilution of component 2 , and the temperatures were between the triple point temperature and the critical temperature of the highboiling component 1 . The upper limit of the concentration of the low-boiling component 2 was determined by the occurrence of a critical point or a three-phase line. For more details see Ref. [27]. For low-boiling azeotropic systems, the model should be applied taking the azeotropic point into account, i.e. the low-boiling component has to be assigned to each branch separately. However, such data is presently very scarce, see electronic Supplementary Material. Furthermore, reference data was available for $0<K_{2}^{5 \%}<15$. It is noted that neither the training-dataset nor the test-dataset contain data points with $\Delta \tilde{\rho}_{2}<0$ and $K_{2}^{5 \%}<10$. Hence, the empirical enrichment model is not valid in that region. We therefore assume that, if such data exist at all, they are rare. But should they exist, the model would probably not describe them well. Likewise, the performance of the enrichment model at high-pressure phase equilibria comprising isopycnic states is presently unknown.

Fig. 5 depicts the enrichment determined from the empirical model as a function of the liquid phase concentration $x_{2}^{\prime}$ and the partition coefficient $K_{2}^{5 \%}$ - also extrapolating into the region $K_{2}^{5 \%}>15$.

The plot shown in Fig. 5 was obtained for Delta $\Delta \tilde{\rho}_{2}=0.1$ or $\Delta \tilde{\rho}_{2}=-0.1$, respectively. Due to the character of the Eqs. (2) - (8) other choices of $\Delta \tilde{\rho}_{2}$ yield similar results as long as the sign of $\Delta \tilde{\rho}_{2}$ is the same. Only for $\Delta \tilde{\rho}_{2}$ values with a very small absolute value $\left|\Delta \tilde{\rho}_{2}\right|<0.01$, there is a smooth transition between the branches, which is numerically convenient.

For $K_{2}^{5 \%}<12$ and $\Delta \tilde{\rho}_{2}>0$ (the region where only a single branch exists), the model converges to unity with decreasing $K_{2}^{5 \%}$ at infinite dilution of component 2 . For the composition dependency, the model decreases monotonically to approximately unity for all $K_{2}^{5 \%}$ and $\Delta \tilde{\rho}_{2}$ with increasing $x_{2}^{\prime}$. At infinite dilution of component 2, the enrichment model yields $E_{2}=4.3$ at $K_{2}^{5 \%}=15$ and $\Delta \tilde{\rho}_{2}>0$ (upper branch depicted in Fig. 5). At infinite dilution of component 2 at $\Delta \tilde{\rho}_{2}<0$ (bottom branch in Fig. 5), the enrichment model converges to approximately $E_{2}=1.4$ with increasing $K_{2}^{5 \%}$. 


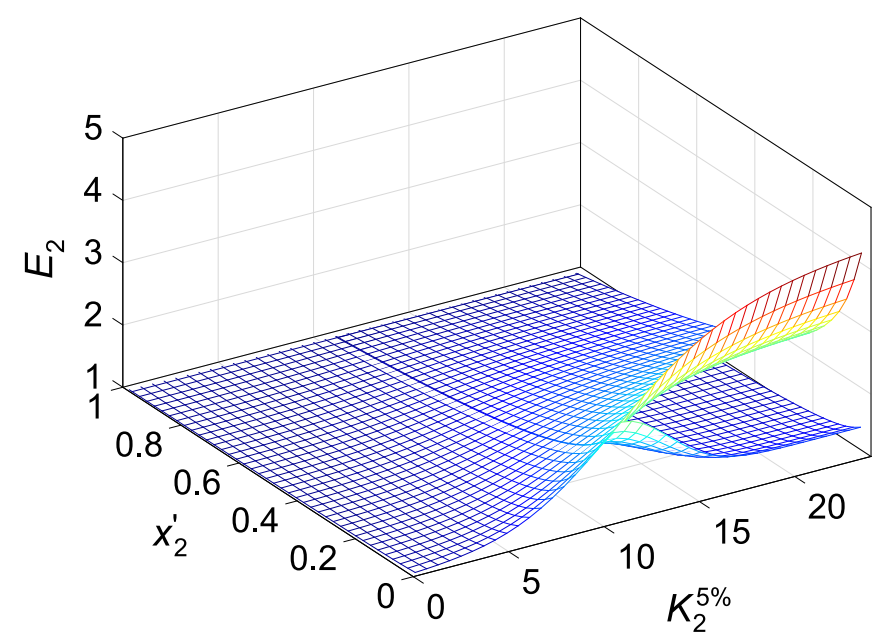

Figure 5. Results of the empirical enrichment model $E_{2}=E_{2}\left(x_{2}^{\prime}, K_{2}^{5 \%}\right)$. Results are shown for $\Delta \tilde{\rho}_{2}=0.1$ and -0.1 . The colour coding refers to the magnitude of $E_{2}$. The branches of the graph for $K_{2}^{5 \%}>12$ correspond to $\Delta \tilde{\rho}_{2}<0$ (low $\left.E_{2}\right)$ and $\Delta \tilde{\rho}_{2}>0$ (high $E_{2}$ ), cf. Eq. (5).

The empirical enrichment model is compared to the training-dataset in Fig. 4. The enrichment model generally describes the influence of the composition, the temperature, and the partition coefficient on $E_{2}$ well. However, Fig. 4 b) shows deviations for the composition dependency for isotherms that exhibit a critical point. Figs. 4 c) and d) show that the temperature dependency is captured reasonably well by the model. Fig. 4 e) shows the enrichment as a function of $K_{2}^{5 \%}$, i.e. the performance of the term $f_{b}\left(K_{2}^{5 \%}\right)$ in Eq. (2). Deviations are observed for data points $K_{2}^{5 \%}>12$, which is mainly due to the fact that the training data was sparsely populated in that region. Figs. 4 a) - e) contain data points from a large range of temperatures and large variety of mixture types, which are described well by the empirical enrichment model. Hence, the implicit temperature dependency of the model via $K_{2}^{5 \%}(T)$ is found to perform astonishingly well, considering the fact that both the influence of the temperature and the mixture type is taken into account only by $K_{2}^{5 \%}$.

Fig. 6 shows the deviation plots for the performance of the empirical enrichment model on the training data. The fit yields an absolute average deviation of $\mathrm{AAD}_{E_{2}}=6.5 \%$. Fig. 6 a) shows the absolute deviation $\Delta E_{2}$ as a function of the partition coefficient $K_{2}^{5 \%}$ (for different $T$ and $x_{2}^{\prime}$ ); Fig. 6 b) shows $\Delta E_{2}$ as a function of the liquid phase concentration $x_{2}^{\prime}$ (for different $T$ and $K_{2}^{5 \%}$ ); and Fig. 6 c) shows the absolute deviation $\Delta E_{2}$ as a function of the enrichment $E_{2}$ itself (for different $T, x_{2}^{\prime}$, and $K_{2}^{5 \%}$ ). The model captures generally the enrichment behaviour well. The largest absolute deviations are observed for high values of $E_{2}$ and high values $K_{2}^{5 \%}$ and are about 0.75 . The model slightly underestimates the training data in the range $E_{2}=1.2 . .2 .5$ and slightly overestimates the training data for $E_{2}>2.5$.

Assessing the performance of the empirical model, it should be kept in mind that the MD data that were used here as training data, deviate also from the corresponding data obtained by DGT by up to $\left|E_{2}^{\mathrm{MD}}-E_{2}^{\mathrm{DGT}}\right|=1[14,25,27]$ (indicated by the dashed lines in Fig. 6) which is more than the largest 

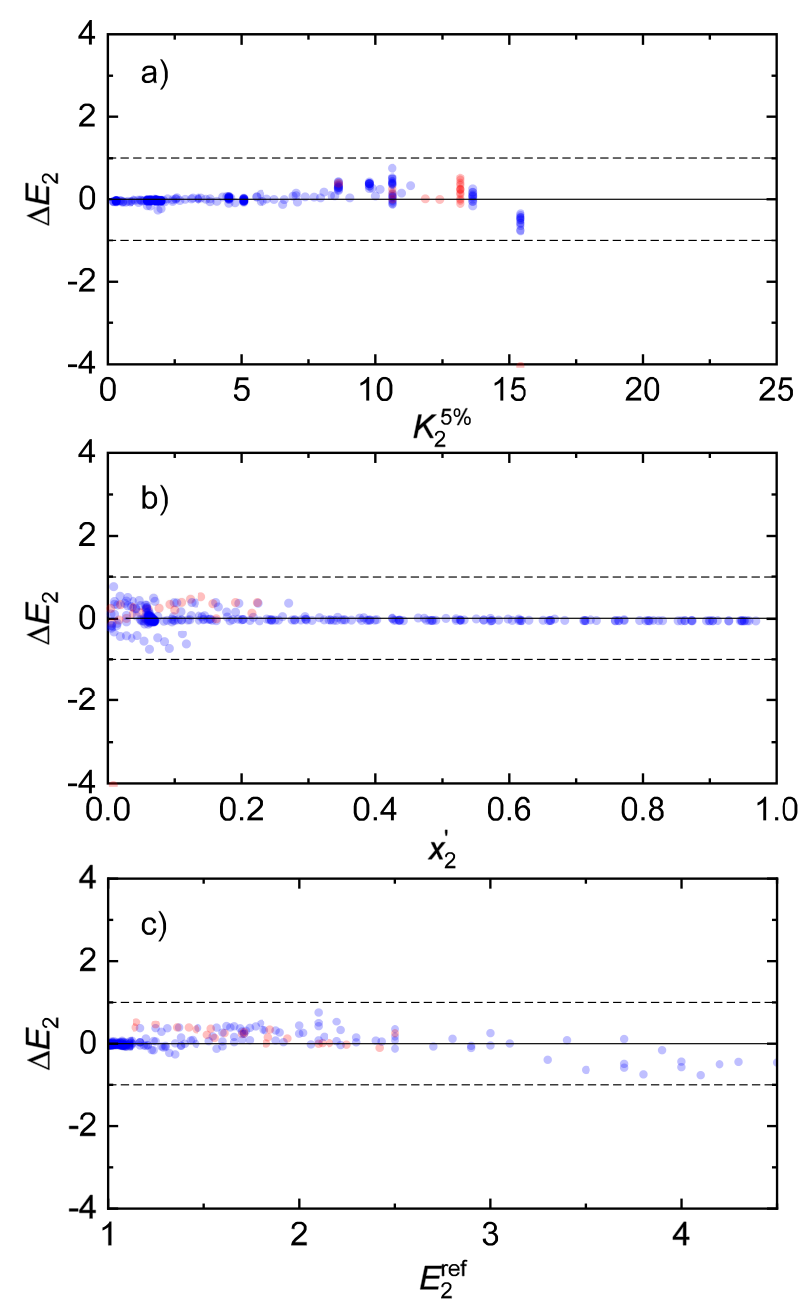

Figure 6. Deviation plots of the enrichment data from the training-dataset (MD data from Refs. [14, 25, 27]) and the results from the empirical model: a) shows the absolute deviation $\Delta E_{2}$ as a function of the partition coefficient $K_{2}^{5 \%}$; b) shows $\Delta E_{2}$ as a function of the liquid phase concentration $x_{2}^{\prime} ; \mathrm{c}$ ) shows $\Delta E_{2}$ as a function of the enrichment $E_{2}$ itself. Red indicates data points with $\Delta \tilde{\rho}_{2}<0$ and blue data points with $\Delta \tilde{\rho}_{2}>0$. The dashed lines indicate $\delta E_{2}= \pm 1$, which corresponds to the uncertainty of the data.

deviations of the empirical model to the training data. Furthermore, the MD results exhibit statistical uncertainties from the simulation sampling of up to $\delta E_{2}= \pm 0.1$.

Fig. 7 depicts the histogram of the absolute deviations of the enrichment obtained from the empirical model $E_{2}^{\text {model }}$ and the corresponding training-dataset values $E_{2}^{\text {ref }} .97 .3 \%$ of the data points of the trainingdataset are described with an absolute deviation below $\left|\Delta E_{2}\right|=0.5$. For the majority of the data points with $\left|\Delta E_{2}\right|>0.5$, the empirical model slightly underestimates the training data.

\section{Testing the Model Predictions}

The empirical enrichment model was tested on available enrichment data for binary mixtures from the literature, cf. Table 1 - excluding the training-dataset from Refs. [14, 25, 27].

The test-dataset comprises data on real mixtures as well as on model mixtures, e.g. LJ mixtures. For applying the model, VLE data on the mixtures is needed. For the real mixtures, the VLE data was taken 


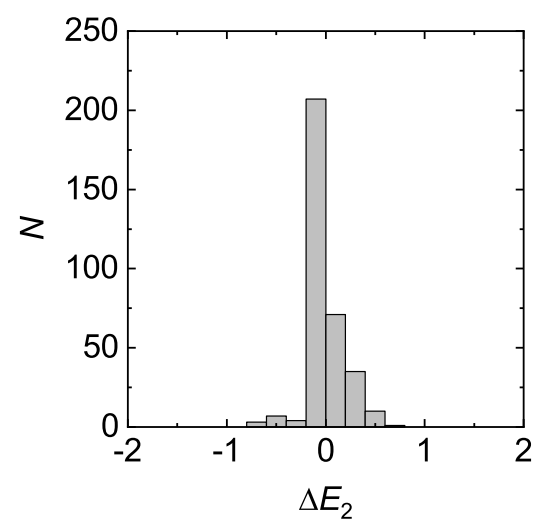

Figure 7. Histogram of the absolute deviations $\Delta E_{2}=E_{2}^{\text {ref }}-E_{2}^{\text {model }}$ of the empirical enrichment model from the training-dataset. The bin width is 0.2 .

from thermophysical property databases [209, 210]; for the model mixtures, the vast majority of publications reporting vapour-liquid density profiles also report the corresponding $T, x^{\prime}, x^{\prime \prime}$-data, which was employed here. $2 \%$ of the enrichment data points of the test-dataset (cf. Table 1) could not be used for the testing of the empirical model, as no $T, x^{\prime}, x^{\prime \prime}$-data for the calculation of $K_{2}^{5 \%}(T)$ was available. In many cases the VLE data - required for the computation of the partition coefficient - was not available at exactly $x_{2}^{\prime}=0.05 \mathrm{~mol} \mathrm{~mol}^{-1}$ and the required temperature. The required input was estimated from the available data as described in more detail in the Supplementary Material.

Fig. 8 shows the histogram of the absolute deviations of the enrichment predicted from the empirical model $E_{2}^{\text {model }}$ and the reference values $E_{2}^{\text {ref }}$ from the test-dataset. The absolute average deviation is $\mathrm{AAD}_{E_{2}}=16.1 \%$, which is astonishingly low considering the fact that the empirical model was trained to an MD dataset based on purely dispersively interacting fluids, whereas the test-dataset contains a large variety of molecular interactions, mixture types, and employed methods. $84 \%$ of the data points are described within an absolute deviation of $\Delta E_{2}= \pm 0.5$ by the empirical model. Hence, the empirical model predicts the enrichment of a low-boiling component $E_{2}$ practically within the uncertainty of the determination of $E_{2}$ with different theoretical methods. However, as found for the performance on the training-dataset, the empirical model shows a trend to slightly overestimate the enrichment.

The performance of the model predictions are analysed in more detail in Fig. 9, which shows the deviation plots for $E_{2}$ predicted by the empirical model and the values from the test-dataset. Its layout is analogue to that of Fig. 6. Fig. 9 a) shows the absolute deviation $\Delta E_{2}$ as a function of the partition coefficient $K_{2}^{5 \%}$; Fig. 9 b) shows $\Delta E_{2}$ as a function of the liquid phase concentration $x_{2}^{\prime}$; and Fig. 9 c) shows the absolute deviation $\Delta E_{2}$ as a function of the enrichment $E_{2}$ itself. Absolute deviations $\Delta E_{2}>1$ are mainly found for large partition coefficients $K_{2}^{5 \%}$, low $x_{2}^{\prime}$, and large $E_{2}$, which is attributed to simplifications in the term $f_{b}$ in the empirical model. Also, this is likely due to the fact that the training-dataset has only a relatively small amount of data points at large $K_{2}^{5 \%}>12$ and the fact that the model was applied to predict data 


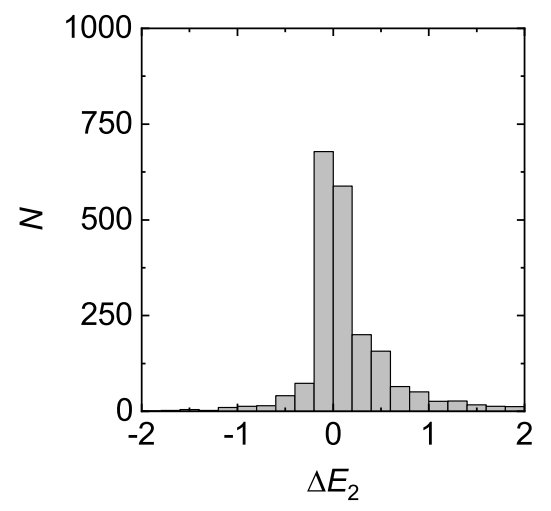

Figure 8. Histogram of the absolute deviations $\Delta E_{2}=E_{2}^{\text {ref }}-E_{2}^{\text {model }}$ of the predictions of the empirical enrichment model to the data from the test-dataset (cf. Table 1). The bin width is 0.2 .

points with $K_{2}^{5 \%}>15$. For mixtures with low $K_{2}^{5 \%}$, the model performs very well.

From Figs. 9 a) - c), it becomes clear that the empirical model slightly overestimates the enrichment for most data points - especially data points with $\Delta \tilde{\rho}_{2}<0$, whereas data points with $\Delta \tilde{\rho}_{2}>0$ are mostly slightly underestimated. Some of the few outliers that can be seen in Fig. 9 might be due to the digitalisation, see Supplementary Material for a detailed discussion.

The lined-up data points in Fig. 9 c) correspond to enrichment isotherms obtained from DGT from Refs. [15-17, 181]. In most cases, they are predicted well by the empirical model in a large composition range, but deviations are observed for high $E_{2}$. For low $E_{2}$ values, the empirical model correctly predicts the vast majority of reference values within an absolute deviation of $\Delta E_{2}= \pm 0.3$, which is surprisingly good since even the deviations between the DGT and MD data often exceed that range. 

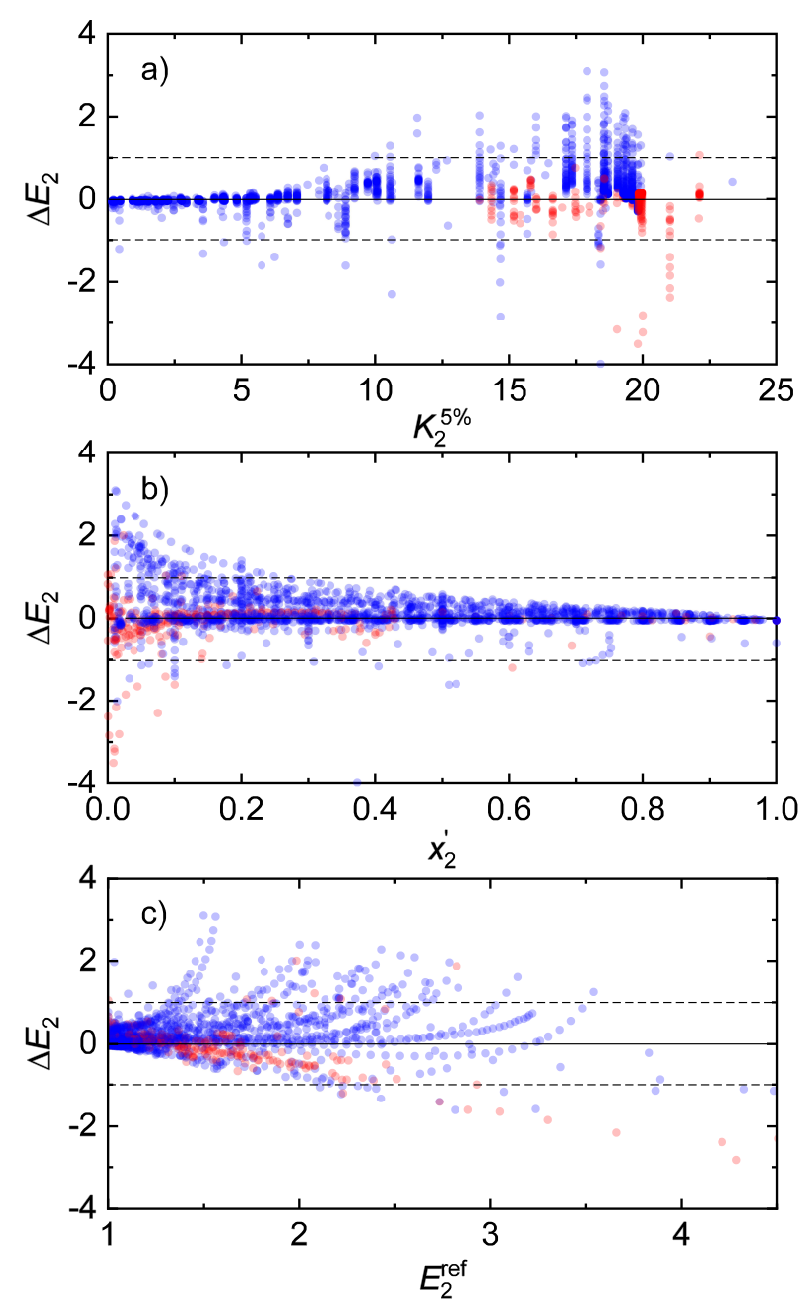

Figure 9. Deviation plots of the enrichment data from the test-dataset (cf. Table 1) and the predictions from the empirical model: a) shows the absolute deviation $\Delta E_{2}$ as a function of the partition coefficient $K_{2}^{5 \%}$; b) shows $\Delta E_{2}=E_{2}^{\text {ref }}-E_{2}^{\text {model }}$ as a function of the liquid phase concentration $x_{2}^{\prime}$; c) shows $\Delta E_{2}$ as a function of the enrichment $E_{2}$ itself. Data that were used for the training of the empirical model $[14,25,27]$ is not shown. Red indicates data points with $\Delta \tilde{\rho}_{2}<0$ and blue data points with $\Delta \tilde{\rho}_{2}>0$. The dashed lines indicate $\delta E_{2}= \pm 1$, which corresponds to the uncertainty of the reference data.

\section{Conclusions and Future Work}

The starting point of the present work is a review of the enrichment of components at vapour-liquid interfaces and of such data available in the literature. The enrichment is defined quantitatively and is a measure for the non-monotonicity of the component density profile in the interfacial region. The enrichment is a highly interesting property as it is believed to influence the mass transfer across interfaces $[10,12,25$, 26, 32-36]. We have digitalised component density profiles from more than 100 publications and have used the profiles to determine the enrichment for about 2300 data points. The established database is supplied in the electronic Supplementary Material. The enrichment predicted from independent theoretical methods usually agrees within $\delta E_{2}= \pm 1$. The values of the enrichment lie mostly in the range $1<E_{2}<10$.

The determination of the enrichment for a given system is presently tedious as it can only be achieved by complex theoretical methods. Therefore, an empirical short-cut method was developed in the present work to estimate the enrichment (a nanoscopic property) solely from macroscopic vapour-liquid equilibrium data 
for a given mixture. The database on the enrichment data established in the present work was therefore split into a training-set and a test-set. The training-set consists of data from comprehensive studies on binary Lennard-Jones mixtures [14, 25, 27] (approximately 300 data points). The test-set contains all remaining data on the enrichment available in the literature (approximately 2000 data points). The empirical model describes the enrichment of the training-dataset with an AAD of $6.5 \%$. The vast majority of data points is described by the empirical model with an error of $\Delta E_{2}= \pm 0.5$, which is well below the uncertainty of the reference data. Applying the empirical model on the test-dataset yields an AAD of $16.1 \%$, whereat $84 \%$ of the data points are described within $\Delta E_{2}= \pm 0.5$. This is remarkable considering the fact that the enrichment model characterises a mixture only by its partition coefficient at $x_{2}^{\prime}=0.05 \mathrm{~mol} \mathrm{~mol}^{-1} K_{2}^{5 \%}$ and the density difference in the bulk phases $\Delta \rho_{2}=\rho_{2}^{\prime}-\rho_{2}^{\prime \prime}$ of the low-boiling component 2. Moreover, for $\Delta \rho_{2}$, basically only the sign has to be known. As further input for the model only the liquid phase concentration $x_{2}^{\prime}$ is needed. The model gets its information on the temperature only indirectly, through the specification of $K_{2}^{5 \%}$, which depends on the temperature. Hence, the model is designed in a way that the enrichment can be computed from the bulk compositions and densities solely, which is available in thermophysical property databases for a large number of systems.

For future work, it would be interesting to extend the dataset employed for the training of the model to systems with $K_{2}^{5 \%}>15$, i.e. particularly wide-boiling phase behaviour, comprising mixtures with $\Delta \rho_{2}>0$ and $\Delta \rho_{2}<0$ as well as azeotropic systems. Furthermore, the performance of the model could probably be further improved by extending the model such that information on the critical composition or the threephase equilibrium (if present) are incorporated. However, this would have the drawback that such data is not as readily available for most mixtures.

Finally, we would like to emphasise that it would be desirable that data on density profiles or profiles of other thermodynamic properties in interfacial regions, which is obtained by costly simulations, should be reported electronically. This has often not been the case in the past such that the vast majority of the corresponding data that has been obtained in previous studies by expensive simulations is now lost for the community.

Based on the developed enrichment model, it was shown, that the nanoscopic enrichment is closely linked to the macroscopic phase behaviour. This knowledge can be used for the screening of systems to identify mixtures with large enrichment. 


\section{Acknowledgements}

\section{Appendix - Definition of the Relative Adsorption}

The relative adsorption $\Gamma_{2}^{(1)}$ characterises - as the enrichment $E_{2}$ - the surface excess of a low-boiling component on a vapour-liquid interface. It can be computed from the macroscopic and the nanoscopic definition. The first approach follows the Gibbs adsorption equation, which relates the relative adsorption to the dependency of the surface tension of the chemical potential [77]. The relative adsorption $\Gamma_{2}^{(1)}$ is thereby defined as

$$
\Gamma_{2}^{(1)}=-\left(\frac{\partial \gamma}{\partial \mu_{2}}\right)_{T}
$$

where $\mu_{2}$ is the chemical potential of component 2 in the equilibrated phases. Hence, the relative adsorption can be obtained from the experimental surface tension data in combination with a thermodynamic model for the bulk phases.

The nanoscopic definition relates the relative adsorption to the component density profiles $\rho_{i}(z)$ at a fluid interface (with high-boiling and low-boiling component $i=1,2$, respectively). $\Gamma_{2}^{(1)}$ can be computed by the symmetric interface segregation according to Telo da Gama and Evans [10]

$$
\Gamma_{2}^{(1)}=-\left(\rho_{2}^{\prime}-\rho_{2}^{\prime \prime}\right) \int_{-\infty}^{\infty}\left[\frac{\rho_{1}(z)-\rho_{1}^{\prime}}{\rho_{1}^{\prime}-\rho_{1}^{\prime \prime}}-\frac{\rho_{2}(z)-\rho_{2}^{\prime}}{\rho_{2}^{\prime}-\rho_{2}^{\prime \prime}}\right] \mathrm{d} z
$$

where $\rho_{1}^{\prime}, \rho_{1}^{\prime \prime}$ and $\rho_{2}^{\prime}, \rho_{2}^{\prime \prime}$ are the component densities at saturation in the two coexisting bulk phases ' ${ }^{\prime}$ and ", respectively.

\section{Disclosure statement}

No potential conflict of interest was reported by the authors.

\section{Funding}

This work was supported by the European Research Council under the Advanced Grant ENRICO [No. $694807]$. 


\section{References}

[1] Andersson G, Krebs T, Morgner H. Activity of surface active substances determined from their surface excess. Physical Chemistry Chemical Physics. 2005;7(1):136.

[2] Ishiyama T, Morita A, Miyamae T. Surface structure of sulfuric acid solution relevant to sulfate aerosol: Molecular dynamics simulation combined with sum frequency generation measurement. Physical Chemistry Chemical Physics. 2011;13(47):20965.

[3] Saito K, Peng Q, Qiao L, Wang L, Joutsuka T, Ishiyama T, Ye S, Morita A. Theoretical and experimental examination of SFG polarization analysis at acetonitrile-water solution surfaces. Physical Chemistry Chemical Physics. 2017;19(13):8941-8961.

[4] Gopalakrishnan S, Liu D, Allen HC, Kuo M, Shultz MJ. Vibrational spectroscopic studies of aqueous interfaces: Salts, acids, bases, and nanodrops. Chemical Reviews. 2006;106(4):1155-1175.

[5] Shultz MJ, Schnitzer C, Simonelli D, Baldelli S. Sum frequency generation spectroscopy of the aqueous interface: Ionic and soluble molecular solutions. International Reviews in Physical Chemistry. 2000;19(1):123-153.

[6] Stocco A, Tauer K. High-resolution ellipsometric studies on fluid interfaces. The European Physical Journal E. 2009;30(4):431.

[7] Telo da Gama MM, Evans R. Theory of the liquid-vapour interface of a binary mixture of Lennard-Jones fluids. Molecular Physics. 1980;41(5):1091-1112.

[8] Carey BS, Scriven LE, Davis HT. Semiempirical theory of surface tension of binary systems. AIChE Journal. 1980;26(5):705-711.

[9] Falls AH, Scriven LE, Davis HT. Adsorption, structure, and stress in binary interfaces. The Journal of Chemical Physics. 1983;78(12):7300-7317.

[10] Telo da Gama MM, Evans R. The structure and surface tension of the liquid-vapour interface near the upper critical end point of a binary mixture of Lennard-Jones fluids I. the two phase region. Molecular Physics. 1983; 48(2):229-250.

[11] Telo da Gama MM, Evans R. The structure and surface tension of the liquid-vapour interface near the upper critical end point of a binary mixture of Lennard-Jones fluids II. the three phase region and the Cahn wetting transition. Molecular Physics. 1983;48(2):251-266.

[12] Lee DJ, Telo da Gama MM, Gubbins KE. The vapour-liquid interface for a Lennard-Jones model of argonkrypton mixtures. Molecular Physics. 1984;53(5):1113-1130.

[13] Lee DJ, Telo da Gama MM, Gubbins KE. Adsorption and surface tension reduction at the vapor-liquid interface. The Journal of Physical Chemistry. 1985;89(8):1514-1519.

[14] Stephan S, Hasse H. Molecular interactions at vapor-liquid interfaces: Binary mixtures of simple fluids. Physical Review E. 2020;101:012802.

[15] Stephan S, Becker S, Langenbach K, Hasse H. Vapor-liquid interfacial properties of the binary system cyclohexane + CO2: Experiment, molecular simulation and density gradient theory. Fluid Phase Equilibria. 2020; $518: 112583$. 
[16] Werth S, Kohns M, Langenbach K, Heilig M, Horsch M, Hasse H. Interfacial and bulk properties of vaporliquid equilibria in the system toluene+hydrogen chloride+carbon dioxide by molecular simulation and density gradient theory + PC-SAFT. Fluid Phase Equilibria. 2016;427:219.

[17] Becker S, Werth S, Horsch M, Langenbach K, Hasse H. Interfacial tension and adsorption in the binary system ethanol and carbon dioxide: Experiments, molecular simulation and density gradient theory. Fluid Phase Equilibria. 2016;427:476.

[18] Müller EA, Mejía A. Interfacial properties of selected binary mixtures containing n-alkanes. Fluid Phase Equilibria. $2009 ; 282(2): 68-81$.

[19] Míguez JM, Garrido JM, Blas FJ, Segura H, Mejía A, Piñeiro MM. Comprehensive characterization of interfacial behavior for the mixture $\mathrm{CO} 2+\mathrm{H} 2 \mathrm{O}+\mathrm{CH} 4$ : Comparison between atomistic and coarse grained molecular simulation models and density gradient theory. The Journal of Physical Chemistry C. 2014;118(42):2450424519.

[20] Mejía A, Cartes M, Segura H, Müller EA. Use of equations of state and coarse grained simulations to complement experiments: Describing the interfacial properties of carbon dioxide + decane and carbon dioxide + eicosane mixtures. Journal of Chemical \& Engineering Data. 2014;59(10):2928.

[21] Ghobadi AF, Elliott JR. Adapting SAFT- $\gamma$ perturbation theory to site-based molecular dynamics simulation. II. confined fluids and vapor-liquid interfaces. The Journal of Chemical Physics. 2014;141(2):024708.

[22] Miqueu C, Miguez JM, Piñeiro MM, Lafitte T, Mendiboure B. Simultaneous application of the gradient theory and Monte Carlo molecular simulation for the investigation of methane/water interfacial properties. The Journal of Physical Chemistry B. 2011;115(31):9618-9625.

[23] Choudhary N, Nair AKN, Ruslan MFAC, Sun S. Bulk and interfacial properties of decane in the presence of carbon dioxide, methane, and their mixture. Scientific Reports. 2019;9(1):1-10.

[24] Mejía A, Pàmies JC, Duque D, Segura H, Vega LF. Phase and interface behaviors in type-I and type-V Lennard-Jones mixtures: Theory and simulations. The Journal of Chemical Physics. 2005;123(3):034505.

[25] Stephan S, Langenbach K, Hasse H. Interfacial properties of binary Lennard-Jones mixtures by molecular simulations and density gradient theory. The Journal of Chemical Physics. 2019;150(17):174704.

[26] Stephan S, Langenbach K, Hasse H. Enrichment of components at vapour-liquid interfaces: A study by molecular simulation and density gradient theory. Chemical Engineering Transactions. 2018;69:295-300.

[27] Stephan S, Hasse H. Interfacial properties of binary mixtures of simple fluids and their relation to the phase diagram. Physical Chemistry Chemical Physics. 2020;22(22):12544-12564.

[28] Carey B. The gradient theory of fluid interfaces [dissertation]. Minneapolis: University of Minnesota; 1979.

[29] Cornelisse PM. The square gradient theory applied simultaneous modelling of interfacial tension and phase behaviour [dissertation]. Technische Universiteit Delft; 1997.

[30] Miqueu C, Mendiboure B, Graciaa C, Lachaise J. Modelling of the surface tension of binary and ternary mixtures with the gradient theory of fluid interfaces. Fluid Phase Equilibria. 2004;218(2):189-203.

[31] Enders S, Quitzsch K. Calculation of interfacial properties of demixed fluids using density gradient theory. Langmuir. 1998;14(16):4606-4614. 
[32] Klink C, Gross J. A density functional theory for vapor-liquid interfaces of mixtures using the perturbed-chain polar statistical associating fluid theory equation of state. Industrial \& Engineering Chemistry Research. 2014; $53(14): 6169$.

[33] Nagl R, Zimmermann P, Zeiner T. Interfacial mass transfer in water-toluene systems. Journal of Chemical \& Engineering Data. 2020;65(2):328-336.

[34] Garrido JM, Piñeiro MM, Mejía A, Blas FJ. Understanding the interfacial behavior in isopycnic Lennard-Jones mixtures by computer simulations. Physical Chemistry Chemical Physics. 2016;18:1114-1124.

[35] Enders S, Kahl H. Interfacial properties of water + alcohol mixtures. Fluid Phase Equilibria. 2008;263(2):160167.

[36] Karlsson B, Friedman R. Dilution of whisky - the molecular perspective. Scientific Reports. 2017;7(6489):1-9.

[37] Chang TM, Peterson KA, Dang LX. Molecular dynamics simulations of liquid, interface, and ionic solvation of polarizable carbon tetrachloride. The Journal of Chemical Physics. 1995;103(17):7502-7513.

[38] Ishiyama T, Morita A. Molecular dynamics analysis of interfacial structures and sum frequency generation spectra of aqueous hydrogen halide solutions. The Journal of Physical Chemistry A. 2007;111(38):9277-9285.

[39] Ishiyama T, Morita A. Molecular dynamics study of gas-liquid aqueous sodium halide interfaces. I. flexible and polarizable molecular modeling and interfacial properties. The Journal of Physical Chemistry C. 2007; $111(2): 721-737$.

[40] Imamura T, Mizukoshi Y, Ishiyama T, Morita A. Surface structures of NaF and Na2SO4 aqueous solutions: Specific effects of hard ions on surface vibrational spectra. The Journal of Physical Chemistry C. 2012; 116(20):11082-11090.

[41] Perez-Blanco ME, Maginn EJ. Molecular dynamics simulations of CO2 at an ionic liquid interface: Adsorption, ordering, and interfacial crossing. The Journal of Physical Chemistry B. 2010;114(36):11827-11837.

[42] Perez-Blanco ME, Maginn EJ. Molecular dynamics simulations of carbon dioxide and water at an ionic liquid interface. The Journal of Physical Chemistry B. 2011;115(35):10488-10499.

[43] Nguyen CV, Nakahara H, Shibata O, Phan CM. Adsorption of sodium iodine at air/water interface. Journal of Molecular Liquids. 2020;298:112076.

[44] Moghimikheirabadi A, Sagis LMC, Kröger M, Ilg P. Gas-liquid phase equilibrium of a model langmuir monolayer captured by a multiscale approach. Physical Chemistry Chemical Physics. 2019;21(5):2295-2306.

[45] Liu ZY, Wang C, Zhou H, Wang Y, Zhang L, Zhang L, Zhao S. Characterizing the impact of surfactant structure on interfacial tension: a molecular dynamics study. Journal of Molecular Modeling. 2017;23(4):112.

[46] Liu ZY, Wei N, Wang C, Zhou H, Zhang L, Liao Q, Zhang L. Interfacial assignment of branched-alkyl benzene sulfonates: A molecular simulation. AIP Advances. 2015;5(11):117203.

[47] Hantal G, Pártay LB, Varga I, Jedlovszky P, Gilányi T. Counterion and surface density dependence of the adsorption layer of ionic surfactants at the vapor-aqueous solution interface: A computer simulation study. The Journal of Physical Chemistry B. 2007;111(7):1769-1774.

[48] Moghimikheirabadi A, Ilg P, Sagis LMC, Kröger M. Surface rheology and structure of model triblock copolymers at a liquid-vapor interface: A molecular dynamics study. Macromolecules. 2020;53(4):1245-1257. 
[49] Kim HY, Fichthorn KA. Molecular dynamics simulation of amphiphilic dimers at a liquid-vapor interface. The Journal of Chemical Physics. 2005;122(3):034704.

[50] Kruber KF, Krapoth M, Zeiner T. Interfacial mass transfer in ternary liquid-liquid systems. Fluid Phase Equilibria. 2017;440:54-63.

[51] Kulaguin-Chicaroux A, Zeiner T. Interfacial behavior of aqueous two-phase systems based on linear and hyperbranched polymers. Journal of Chemical \& Engineering Data. 2018;63(7):2467-2476.

[52] Buhn JB, Bopp PA, Hampe MJ. A molecular dynamics study of a liquid-liquid interface: Structure and dynamics. Fluid Phase Equilibria. 2004;224(2):221-230.

[53] Choi JS, Bae YC. Phase equilibrium and interfacial tension of binary and ternary polymer solutions. Journal of Chemical \& Engineering Data. 2016;61(12):4157-4163.

[54] Telo da Gama MM, Thurtell JH. Interfacial phase transitions in molecular fluids and multicomponent mixtures. J Chem Soc, Faraday Trans 2. 1986;82:1721-1737.

[55] Ghoufi A, Malfreyt P, Tildesley DJ. Computer modelling of the surface tension of the gas-liquid and liquidliquid interface. Chemical Society Reviews. 2016;45:1387-1409.

[56] Lamorgese A, Mauri R, Sagis L. Modeling soft interface dominated systems: A comparison of phase field and Gibbs dividing surface models. Physics Reports. 2017;675:1-54.

[57] Rowlinson JS, Widom B. Molecular theory of capillarity. New York: Dover Publications; 1982.

[58] Evans R. The nature of the liquid-vapour interface and other topics in the statistical mechanics of non-uniform, classical fluids. Advances in Physics. 1979;28(2):143-200.

[59] Evans R. Fundamentals of inhomogeneous fluids. New York: Marcel Dekker; 1992.

[60] Evans R, Henderson JR, Hoyle DC, Parry AO, Sabeur ZA. Asymptotic decay of liquid structure: Oscillatory liquid-vapour density profiles and the Fisher-Widom line. Molecular Physics. 1993;80(4):755-775.

[61] Evans R. Oscillatory behaviour of density profiles: Relevance for fluid interfacial phenomena. Berichte der Bunsengesellschaft für physikalische Chemie. 1994;98(3):345-352.

[62] Stephan S, Liu J, Langenbach K, Chapman WG, Hasse H. Vapor-liquid interface of the Lennard-Jones truncated and shifted fluid: Comparison of molecular simulation, density gradient theory, and density functional theory. The Journal of Physical Chemistry C. 2018;122(43):24705-24715.

[63] Geysermans P, Elyeznasni N, Russier V. Layered interfaces between immiscible liquids studied by densityfunctional theory and molecular-dynamics simulations. The Journal of Chemical Physics. 2005;123(20):204711.

[64] Toxvaerd S, Stecki J. Density profiles at a planar liquid-liquid interface. The Journal of Chemical Physics. $1995 ; 102(18): 7163-7168$.

[65] Díaz-Herrera E, Alejandre J, Ramírez-Santiago G, Forstmann F. Interfacial tension behavior of binary and ternary mixtures of partially miscible Lennard-Jones fluids: A molecular dynamics simulation. The Journal of Chemical Physics. 1999;110(16):8084-8089.

[66] Napari I, Laaksonen A, Talanquer V, Oxtoby DW. A density functional study of liquid-liquid interfaces in partially miscible systems. The Journal of Chemical Physics. 1999;110(12):5906-5912.

[67] Martinez-Ruiz FJ, Moreno-Ventas Bravo AI, Blas FJ. Liquid-liquid interfacial properties of a symmetrical 
Lennard-Jones binary mixture. The Journal of Chemical Physics. 2015;143(10):104706.

[68] Brown JR, Seo Y, Maula TAD, Hall LM. Fluids density functional theory and initializing molecular dynamics simulations of block copolymers. The Journal of Chemical Physics. 2016;144(12):124904.

[69] Winkelmann J. The liquid-vapour interface of pure fluids and mixtures: Application of computer simulation and density functional theory. Journal of Physics: Condensed Matter. 2001;13(21):4739.

[70] Rehner P, Gross J. Predictive density gradient theory based on nonlocal density functional theory. Physical Review E. 2018;98:063312.

[71] Bühl C, Enders S. Prediction of interfacial properties of ternary, sulfur-containing mixtures. Journal of Chemical \& Engineering Data. 2016;61(12):4261-4269.

[72] Mohammed S, Mansoori GA. Molecular insights on the interfacial and transport properties of supercritical CO2/brine/crude oil ternary system. Jorunal of Molecular Liquids. 2018;218:268-273.

[73] Mohammed S, Mansoori G. Effect of CO2 on the interfacial and transport properties of water/binary and asphaltenic oils: Insights from molecular dynamics. Energy \& Fuels. 2018;32(4):5409-5417.

[74] Herdes C, Totton TS, Müller EA. Coarse grained force filed for the molecular simulation of natural gases and condensates. Fluid Phase Equilibria. 2015;406:91-100.

[75] Mairhofer J, Gross J. Modeling of interfacial properties of multicomponent systems using density dradient theory and PCP-SAFT. Fluid Phase Equilibria. 2017;439:31.

[76] Telo da Gama MM, Evans R. Surface segregation and surface tension at the liquid-vapour interface of a binary mixture of Lennard-Jones fluids. Faraday Symposia of The Chemical Society. 1981;16:45-58.

[77] Defay R, Prigogine I, Bellmans A, Everett DH. Surface tension and adsorption. London: Longmans; 1966.

[78] Baidakov VG, Khotienkova MN. Surface tension of methane-nitrogen solutions: 2. description in the framework of the van der Waals gradient theory. Fluid Phase Equilibria. 2016;425:402-410.

[79] Lafitte T, Mendiboure B, Piñeiro MM, Bessières D, Miqueu C. Interfacial properties of water $/ \mathrm{CO}_{2}$ : A comprehensive description through a gradient theory SAFT-VR Mie approach. The Journal of Physical Chemistry B. 2010;114(34):11110-11116.

[80] Mecke M, Winkelmann J, Fischer J. Molecular dynamics simulation of the liquid-vapor interface: Binary mixtures of Lennard-Jones fluids. The Journal of Chemical Physics. 1999;110(2):1188-1194.

[81] Baidakov VG, Protsenko SP. Molecular-dynamics investigation of phase equilibrium and surface tension in argon-neon system. The Journal of Physical Chemistry C. 2008;112(44):17231-17234.

[82] Pereira LM, Chapoy A, Burgass R, Tohidi B. Measurement and modelling of high pressure density and interfacial tension of (gas + n-alkane) binary mixtures. The Journal of Chemical Thermodynamics. 2016;97:55-69.

[83] Algaba J, Cartes M, A M, Miguez JM, Blas FJ. Phase equilibria and interfacial properties of the tetrahydrofuran + methane binary mixture from experiment and computer simulation. The Journal of Physical Chemistry C. 2019;123(34):20960-20970.

[84] Wadewitz T, Winkelmann J. Density functional theory: Structure and interfacial properties of binary mixtures. Berichte der Bunsengesellschaft für physikalische Chemie. 1996;100(11):1825-1832.

[85] Teixeira PIC, Almeida BS, Telo da Gama MM, Rueda JA, Rubio RG. Interfacial properties of mixtures of 
molecular fluids: comparison between theory and experiment; methyl iodide + carbon tetrachloride and acetonitrile + carbon tetrachloride. The Journal of Physical Chemistry. 1992;96(21):8488-8497.

[86] Aracil J, Luengo G, Almeida BS, Telo da Gama MM, Rubio RG, Diaz Pena M. Surface properties of mixtures of molecular fluids: an experimental and theoretical study of carbon disulfide + dichloromethane and carbon disulfide + carbon tetrachloride. The Journal of Physical Chemistry. 1989;93(8):3210-3218.

[87] Liu B, Shi J, Wang M, Zhang J, Sun B, Shen Y, Sun X. Reduction in interfacial tension of water-oil interface by supercritical CO2 in enhanced oil recovery processes studied with molecular dynamics simulation. The Journal of Supercritical Fluids. 2016;111:171-178.

[88] Miqueu C, Mendiboure B, Graciaa A, Lachaise J. Modeling of the surface tension of multicomponent mixtures with the gradient theory of fluid interfaces. Industrial \& Engineering Chemistry Research. 2005;44(9):33213329.

[89] Herdes C, Ervik A, Mejía A, Müller EA. Prediction of the water/oil interfacial tension from molecular simulations using the coarse-grained SAFT- $\gamma$ Mie force field. Fluid Phase Equilibria. 2018;476:9-15.

[90] Zambrano HA, Walther JH, Jaffe RL. Molecular dynamics simulations of water on a hydropholic silicia surface at high air pressures. Journal of Molecular Liquids. 2014;198:107-113.

[91] Telo da Gama MM. Phase equilibria and interfacial properties of model ternary mixtures. Molecular Physics. 1987;62(3):585-604.

[92] Kou J, Sun S, Wang X. Efficient numerical methods for simulating surface tension of multi-component mixtures with the gradient theory of fluid interfaces. Computer Methods in Applied Mechanics and Engineering. 2015; 292:92-106.

[93] Miqueu C, Mendiboure B, Graciaa A, Lachaise J. Petroleum mixtures: An efficient predictive method for surface tension estimations at reservoir conditions. Fuel. 2008;87(6):612-621.

[94] Rohatgi A. Webplotdigitizer ; 2019. Used december 2019; Available from: https://automeris.io/ WebPlotDigitizer.

[95] Niño-Amézquita OG. Interfacial properties and phase equilibria for mixtures relevant in the oil industry [dissertation]. TU Berlin; 2013. Available from: https://depositonce.tu-berlin.de/bitstream/11303/4321/ 1/nino\%20amezquita_oscar $\% 20$ gabriel.pdf.

[96] Niño-Amézquita OG, Enders S. Prediction of interfacial tension of binary mixtures. In: Pierucci S, Ferraris GB, editors. 20th european symposium on computer aided process engineering. (Computer Aided Chemical Engineering; Vol. 28). Elsevier; 2010. p. 85-90.

[97] Llovell F, Dowell NM, Blas FJ, Galindo A, Jackson G. Application of the SAFT-VR density functional theory to the prediction of the interfacial properties of mixtures of relevance to reservoir engineering. Fluid Phase Equilibria. 2012;336(Supplement C):137-150.

[98] Sahimi M, Taylor BN. Surface tension of binary liquid-vapor mixtures: A comparison of mean-field and scaling theories. The Journal of Chemical Physics. 1991;95(9):6749-6761.

[99] Liu ST, Fu D, Lu JY. Investigation of bulk and interfacial properties for nitrogen and light hydrocarbon binary mixtures by perturbed-chain statistical associating fluid theory combined with density-gradient theory. 
Industrial \& Engineering Chemistry Research. 2009;48(23):10734-10739.

[100] Garrido JM, Cartes M, Mejía A. Coarse-grained theoretical modeling and molecular simulations of nitrogen + n-alkanes: (n-pentane, n-hexane, n-heptane, n-octane). The Journal of Supercritical Fluids. 2017;129:83-90.

[101] Bühl C, Danzer A, Enders S. Prediction of surface properties of binary, sulfur containing mixtures. Fluid Phase Equilibria. 2016;416:94-103.

[102] Lobanova O, Mejía A, Jackson G, Müller EA. SAFT-i force field for the simulation of molecular fluids 6: Binary and ternary mixtures comprising water, carbon dioxide, and n-alkanes. The Journal of Chemical Thermodynamics. 2016;93:320-336.

[103] Li W, Jin Z. Molecular dynamics simulation of natural gas-water interfacial tensions over wide range of pressures. Fuel. 2019;236:480-492.

[104] Naeiji P, Woo T, Alavi S, Varaminian F, Ohmura R. Interfacial properties of hydrocarbon/water systems predicted by molecular dynamic simulations. Journal of Chemical Physics. 2019;150(11):114703.

[105] Khosharay S, Rezakhani N. Using a new proposed influence parameter of gradient theory for CH4/n-alkane binary systems: What advances can be achieved? Periodica Polytechnica Chemical Engineering. 2016;60(4):282289.

[106] Niño-Amézquita OG, van Putten D, Enders S. Phase equilibrium and interfacial properties of water $+\mathrm{CO}_{2}$ mixtures. Fluid Phase Equilibria. 2012;332:40.

[107] Chow YTF, Eriksen DK, Galindo A, Haslam AJ, Jackson G, Maitland GC, Trusler JP. Interfacial tensions of systems comprising water, carbon dioxide and diluent gases at high pressures: Experimental measurements and modelling with SAFT-VR Mie and square-gradient theory. Fluid Phase Equilibria. 2016;407:159-176.

[108] Li XS, Liu JM, Fu D. Investigation of interfacial tensions for carbon dioxide aqueous solutions by perturbedchain statistical associating fluid theory combined with density-gradient theory. Industrial \& Engineering Chemistry Research. 2008;47(22):8911-8917.

[109] Biscay F, Ghoufi A, Lachet V, Malfreyt P. Monte Carlo simulations of the pressure dependence of the water-acid gas interfacial tensions. The Journal of Physical Chemistry B. 2009;113(43):14277-14290.

[110] Neyt JC, Wender A, Lachet V, Malfreyt P. Modeling the pressure dependence of acid gas + n-alkane interfacial tensions using atomistic Monte Carlo simulations. Journal of Physical Chemistry. 2012;116(19):10563-10572.

[111] Chen C, Hu W, Li W, Song Y. Model comparison of the CH4/CO2/water system in predicting dynamic and interfacial properties. Journal of Chemical Engineering Data. 2019;64:2464-2474.

[112] Fouad WA, Vega LF. The phase and interfacial properties of azeotropic refrigerants: the prediction of aneotropes from molecular theory. Physical Chemistry Chemical Physics. 2017;19:8977-8988.

[113] Li Y, Fouad WA, Vega LF. Interfacial anomaly in low global warming potential refrigerant blends as predicted by molecular dynamics simulations. Physical Chemistry Chemical Physics. 2019;21(39):22092-22102.

[114] Vilaseca O, Llovell F, Yustos J, Marcos RM, Vega LF. Phase equilibria, surface tensions and heat capacities of hydrofluorocarbons and their mixtures including the critical region. The Journal of Supercritical Fluids. 2010; $55(2): 755-768$.

[115] Khosharay S, Mazraeno MS, Varaminian F, Bagheri A. A proposed combination model for predicting surface 
tension and surface properties of binary refrigerant mixtures. International Journal of Refrigeration. 2014; 40:347-361.

[116] Zeng XC, Oxtoby DW. Binary homogeneous nucleation theory for the gas-liquid transition: A nonclassical approach. The Journal of Chemical Physics. 1991;95(8):5940-5947.

[117] Horváth RA, Fábián B, Szőri M, Jedlovszky P. Investigation of the liquid-vapour interface of aqueous methylamine solutions by computer simulation methods. Journal of Molecular Liquids. 2019;288:110978.

[118] Fábián B, Szőri M, Jedlovszky P. Floating patches of HCN at the surface of their aqueous solutions - can they make "HCN world" plausible? The Journal of Physical Chemistry C. 2014;118(37):21469-21482.

[119] Mucha M, Hrobárik T, Jungwirth P. Surface tension from molecular dynamics simulation: Adsorption at the gas-liquid interface. Israel Journal of Chemistry. 2003;43(3-4):393-397.

[120] Koller TM, Yan S, Steininger C, Klein T, Fröba AP. Interfacial tension and liquid viscosity of binary mixtures of n-hexane, n-decane, or 1-hexanol with carbon dioxide by molecular dynamics simulations and surface light scattering. International Journal of Thermophysics. 2019;40(8).

[121] Schäfer E, Sadowski G, Enders S. Interfacial tension of binary mixtures exhibiting azeotropic behavior: Measurement and modeling with PCP-SAFT combined with density gradient theory. Fluid Phase Equilibria. 2014; $362: 151$.

[122] Fu D, Hua X, Xu Y. Cross-association model for the phase equilibria and surface tensions of CO2-methanol and CO2-ethanol mixtures. The Journal of Physical Chemistry C. 2011;115(8):3340-3345.

[123] Eckelsbach S, Vrabec J. Fluid phase interface properties of acetone, oxygen, nitrogen and their binary mixtures by molecular simulation. Physical Chemistry Chemical Physics. 2015;17:27195-27203.

[124] Poser CI, Sanchez IC. Interfacial tension theory of low and high molecular weight liquid mixtures. Macromolecules. 1981;14(2):361-370.

[125] Shi W, Siefert NS, Morreale BD. Molecular simulations of $\mathrm{CO}_{2}, \mathrm{H}_{2}, \mathrm{H}_{2} \mathrm{O}$, and $\mathrm{H}_{2} \mathrm{~S}$ gas absorption into hydrophobic poly(dimethylsiloxane) (pdms) solvent: Solubility and surface tension. The Journal of Physical Chemistry C. $2015 ; 119(33): 19253-19265$.

[126] Telo da Gama MM, Evans R. The density profile and surface tension of a Lennard-Jones fluid from a generalized van der Waals theory. Molecular Physics. 1979;38(2):367-375.

[127] Müller EA, Mejía A. Resolving discrepancies in the measurements of the interfacial tension for the CO2 + H2O mixture by computer simulation. The Journal of Physical Chemistry. 2014;5(7):1267-1271.

[128] Mu X, Frank F, Alpak FO, Chapman WG. Stabilized density gradient theory algorithm for modeling interfacial properties of pure and mixed systems. Fluid Phase Equilibria. 2017;435:118-130.

[129] Breure B, Peters C. Modeling of the surface tension of pure components and mixtures using the density gradient theory combined with a theoretically derived influence parameter correlation. Fluid Phase Equilibria. 2012;334:189-196.

[130] Cao F, Deetz JD, Sun H. Free energy-based coarse-grained force field for binary mixtures of hydrocarbons, nitrogen, oxygen, and carbon dioxide. Journal of Chemical Information and Modeling. 2016;57(1):50-59.

[131] Baidakov VG, Protsenko SP, Bryukhanov VM. Relaxation processes at liquid-gas interfaces in one- and two- 
component Lennard-Jones systems: Molecular dynamics simulation. Fluid Phase Equilibria. 2019;481:1-14.

[132] Duque D, Pamies JC, Vega LF. Interfacial properties of Lennard-Jones chains by direct simulation and density gradient theory. The Journal of Chemical Physics. 2004;121(22):11395-11401.

[133] Garrido JM, Quinteros-Lama H, Piñeiro MM, Mejía A, Segura H. On the phase and interface behavior along the three-phase line of ternary Lennard-Jones mixtures: A collaborative approach based on square gradient theory and molecular dynamics simulations. The Journal of Chemical Physics. 2014;141(1):014503.

[134] Salomons E, Mareschal M. Atomistic simulation of liquid-vapour coexistence: Binary mixtures. Journal of Physics: Condensed Matter. 1991;3(46):9215-9228.

[135] Salomons E, Mareschal M. Surface tension, adsorption and surface entropy of liquid-vapour systems by atomistic simulation. Journal of Physics: Condensed Matter. 1991;3(20):3645-3661.

[136] Protsenko SP, Baidakov VG, Bryukhanov VM. Binary Lennard-Jones mixtures with highly asymmetric interactions of the components. 2. effect of the particle size on phase equilibria and properties of liquid-gas interfaces. Fluid Phase Equilibria. 2016;430:67-74.

[137] Protsenko SP, Baidakov VG. Binary Lennard-Jones mixtures with highly asymmetric interactions of the components. 1. effect of the energy parameters on phase equilibria and properties of liquid-gas interfaces. Fluid Phase Equilibria. 2016;429:242-253.

[138] Martinez-Ruiz FJ, Blas FJ. Interfacial properties of binary mixtures of square-well molecules from Monte Carlo simulation. The Journal of Chemical Physics. 2016;144(15):154705.

[139] Mejía A, Cartes M, Segura H. Interfacial tensions of binary mixtures of ethanol with octane, decane, dodecane, and tetradecane. The Journal of Chemical Thermodynamics. 2011;43(9):1395-1400.

[140] Kahl H, Enders S. Interfacial properties of binary mixtures. Physical Chemistry Chemical Physics. 2002;4:931936.

[141] Niño-Amézquita OG, Enders S. Phase equilibrium and interfacial properties of water+methane mixtures. Fluid Phase Equilibria. 2016;407:143-151.

[142] Stephan S, Hasse H. Influence of dispersive long-range interactions on properties of vapour-liquid interfaces of binary Lennard-Jones mixtures. Molecular Physics. 2019;187:1-14.

[143] Llovell F, Galindo A, Blas FJ, Jackson G. Classical density functional theory for the prediction of the surface tension and interfacial properties of fluids mixtures of chain molecules based on the statistical associating fluid theory for potentials of variable range. The Journal of Chemical Physics. 2010;133(2):024704.

[144] Martinez-Ruiz FJ, Blas FJ, Moreno-Ventas Bravo AI, Miguez JM, MacDowell LG. Vapour-liquid interfacial properties of square-well chains from density functional theory and Monte Carlo simulation. Physical Chemistry Chemical Physics. 2017;19:12296-12309.

[145] Neyt JC, Wender A, Lachet V, Ghoufi A, Malfreyt P. Molecular modeling of the liquid-vapor interfaces of a multi-component mixture: Prediction of the coexisting densities and surface tensions at different pressures and gas compositions. The Journal of Chemical Physics. 2013;139(2):024701.

[146] Lin H, Duan YY, Min Q. Gradient theory modeling of surface tension for pure fluids and binary mixtures. Fluid Phase Equilibria. 2007;254(1):75. 
[147] Cornelisse PM, Peters CJ, de Swaan Arons J. Interfacial phase transitions at solid-fluid and liquid-vapor interfaces. International Journal of Thermophysics. 1998;19(6):1501-1509.

[148] Eggimann BL, Sunnarborg AJ, Stern HD, Bliss AP, Siepmann JI. An online parameter and property database for the TraPPE force field. Molecular Simulation. 2014;40(1-3):101-105.

[149] Stephan S, Horsch M, Vrabec J, Hasse H. MolMod - an open access database of force fields for molecular simulations of fluids. Molecular Simulation. 2019;45(10):806-814.

[150] Rowlinson JS, Swinton FL. Liquids and liquid mixtures. London: Butterworth; 1982.

[151] Chapman WG, Gubbins KE, Jackson G, Radosz M. SAFT: Equation-of-state solution model for associating fluids. Fluid Phase Equilibria. 1989;52:31-38.

[152] Müller EA, Gubbins KE. Molecular-based equations of state for associating fluids: A review of SAFT and related approaches. Industrial \& Engineering Chemistry Research. 2001;40(10):2193-2211.

[153] Gubbins KE. Perturbation theories of the thermodynamics of polar and associating liquids: A historical perspective. Fluid Phase Equilibria. 2016;416:3-17.

[154] Heier M, Stephan S, Liu J, Chapman WG, Hasse H, Langenbach K. Equation of state for the Lennard-Jones truncated and shifted fluid with a cut-off radius of $2.5 \sigma$ based on perturbation theory and its applications to interfacial thermodynamics. Molecular Physics. 2018;116(15):2083-2094.

[155] Span R, Wagner W, Lemmon E, Jacobsen RT. Multiparameter equation of state - recent trends and future challenges. Fluid Phase Equilibria. 2001;183-184:1.

[156] Span R. Multiparameter equations of state. Berlin: Springer; 2000.

[157] Stephan S, Staubach J, Hasse H. Review and comparison of equations of state for the Lennard-Jones fluid. submitted. 2020;.

[158] Tardón MJ, Garrido JM, Quinteros-Lama H, Mejía A, Segura H. Molar isopycnicity in heterogeneous binary mixtures. Fluid Phase Equilibria. 2012;336:84-97.

[159] Schappals M, Mecklenfeld A, Kröger L, Botan V, Köster A, Stephan S, Garcia EJ, Rutkai G, Raabe G, Klein P, Leonhard K, Glass CW, Lenhard J, Vrabec J, Hasse H. Round robin study: Molecular simulation of thermodynamic properties from models with internal degrees of freedom. Journal of Chemical Theory and Computation. 2017;13(9):4270-4280.

[160] Stephan S, Thol M, Vrabec J, Hasse H. Thermophysical properties of the Lennard-Jones fluid: Database and data assessment. J Chem Inf Model. 2019;59(10):4248-4265.

[161] Abraham M, Apostolov R, Barnoud J, Bauer P, Blau C, Bonvin AM, Chavent M, Chodera J, Condic-Jurkic K, Delemotte L, Grubmueller H, Howard RJ, Jordan EJ, Lindahl E, Ollila OHS, Selent J, Smith DGA, Stansfeld PJ, Tiemann JK, Trellet M, Woods C, Zhmurov A. Sharing data from molecular simulations. Journal of Chemical Information and Modeling. 2019;59(10):4093-4099.

[162] Loeffler HH, Bosisio S, Duarte Ramos Matos G, Suh D, Roux B, Mobley DL, Michel J. Reproducibility of free energy calculations across different molecular simulation software packages. Journal of Chemical Theory and Computation. 2018;14(11):5567-5582.

[163] van Gunsteren WF, Mark AE. Validation of molecular dynamics simulation. The Journal of Chemical Physics. 
1998;108(15):6109-6116.

[164] Eckelsbach S, Janzen T, Köster A, Miroshnichenko S, Muñoz-Muñoz YM, Vrabec J. Molecular models for cyclic alkanes and ethyl acetate as well as surface tension data from molecular simulation. In: Nagel WE, Kröner DH, Resch MM, editors. High performance computing in science and engineering '14. Springer International Publishing; 2014. p. 645-659.

[165] Almeida BS, Telo da Gama MM. Surface tension of simple mixtures: comparison between theory and experiment. The Journal of Physical Chemistry. 1989;93(10):4132-4138.

[166] Chang TM, Dang LX. Liquid-vapor interface of methanol-water mixtures: A molecular dynamics study. The Journal of Physical Chemistry B. 2005;109(12):5759-5765.

[167] Cornelisse PM, Peters CJ, de Swaan Arons J. Simultaneous prediction of phase equilibria, interfacial tension and concentration profiles. Molecular Physics. 1993;80(4):941-955.

[168] Cornelisse PM, Peters CJ, de Swaan Arons J. Application of the Peng-Robinson equation of state to calculate interfacial tensions and profiles at vapour-liquid interfaces. Fluid Phase Equilibria. 1993;82:119-129.

[169] Greberg H, Paolini GV, Satherley J, Penfold R, Nordholm S. Generalized van der Waals theory of interfaces in simple fluid mixtures. Journal of Colloid and Interface Science. 2001;235(2):334-343.

[170] Ibarra-Tandi B, Lira A, Lopez-Lemus J. Effect of softness on relative adsorption for binary mixtures of simple fluids. Journal of Molecular Liquids. 2013;185:62-69.

[171] Kahl H, Mecke M, Winkelmann J. Prediction of internal structure and properties in fluid model interfaces of binary and ternary liquid mixtures. Fluid Phase Equilibria. 2005;228-229:293-302.

[172] Khosharay S, Abolala M, Varaminian F. Modeling the surface tension and surface properties of $\mathrm{CO}_{2}+\mathrm{H}_{2} \mathrm{O}$ and $\mathrm{H}_{2} \mathrm{~S}+\mathrm{H}_{2} \mathrm{O}$ with gradient theory in combination with sPC-SAFT EOS and a new proposed influence parameter. Journal of Molecular Liquids. 2014;198(Supplement C):292-298.

[173] Khosharay S, Varaminian F. Experimental and modeling investigation on surface tension and surface properties of $(\mathrm{CH} 4+\mathrm{H} 2 \mathrm{O}),(\mathrm{C} 2 \mathrm{H} 6+\mathrm{H} 2 \mathrm{O}),(\mathrm{CO} 2+\mathrm{H} 2 \mathrm{O})$ and $(\mathrm{C} 3 \mathrm{H} 8+\mathrm{H} 2 \mathrm{O})$ from $284.15 \mathrm{~K}$ to $312.15 \mathrm{~K}$ and pressures up to 60 bar. International Journal of Refrigeration. 2014;47:26-35.

[174] Matsumoto M. Molecular dynamics simulation of interphase transport at liquid surfaces. Fluid Phase Equilibria. 1996;125(1):195-203.

[175] Morita A. Molecular dynamics study of mass accommodation of methanol at liquid-vapor interfaces of methanol/water binary solutions of various concentrations. Chemical Physics Letters. 2003;375(1):1-8.

[176] Morita A, Garrett BC. Molecular theory of mass transfer kinetics and dynamics at gas-water interface. Fluid Dynamics Research. 2008;40(7-8):459-473.

[177] Niño-Amézquita OG, Enders S, Jaeger PT, Eggers R. Interfacial properties of mixtures containing supercritical gases. The Journal of Supercritical Fluids. 2010;55(2):724.

[178] Niño-Amézquita OG, Enders S, Jaeger PT, Eggers R. Measurement and prediction of interfacial tension of binary mixtures. Industrial \& Engineering Chemistry Research. 2010;49(2):592-601.

[179] Panayiotou C. Interfacial tension and interfacial profiles: an equation-of-state approach. Journal of Colloid and Interface Science. $2003 ; 267(2): 418-428$. 
[180] Schenk MR, Köddermann T, Kirschner KN, Knauer S, Reith D. Molecular dynamics in the energy sector: Experiment and modeling of the CO2/CH4 mixture. Journal of Chemical \& Engineering Data. 2019;65(3):11171123.

[181] Stephan S, Hasse H. unpublished data of vapor-liquid interfacial properties of the binary systems toluene + CO2 and toluene + N2. 2020;

[182] Stephan S, Hasse H. unpublished data of binary mixtures of Lennard-Jones + dipolar fluids. 2020;.

[183] Sullivan DE. Interfacial density profiles of a binary van der Waals fluid. The Journal of Chemical Physics. 1982; $77(5): 2632-2638$.

[184] Sanchez IC. Statistical thermodynamics of bulk and surface properties of polymer mixtures. Journal of Macromolecular Science, Part B. 1980;17(3):565-589.

[185] Jones J. On the determination of molecular fields. I. from the variation of the viscosity of a gas with temperature. Proc R Soc London Ser A. 1924;106(738):441-462.

[186] Jones J. On the determination of molecular fields. II. from the equation of state of a gas. Proc R Soc London Ser A. 1924;106(738):463-477.

[187] Lennard-Jones JE. Cohesion. Proceedings of the Physical Society. 1931;43(5):461-482.

[188] Johnson JK, Zollweg JA, Gubbins KE. The Lennard-Jones equation of state revisited. Molecular Physics. 1993; $78(3): 591$.

[189] Allen MP, Tildesley DJ. Computer simulation of liquids. Oxford: Oxford University Press; 1989.

[190] Metropolis N, Rosenbluth AW, Rosenbluth MN, Teller AH, Teller E. Equation of state calculations by fast computing machines. The Journal of Chemical Physics. 1953;21(6):1087-1092.

[191] Gross J, Sadowski G. Perturbed-Chain SAFT: An equation of state based on a perturbation theory for chain molecules. Industrial \& Engineering Chemistry Research. 2001;40(4):1244.

[192] Gross J, Sadowski G. Application of the perturbed-chain SAFT equation of state to associating systems. Industrial \& Engineering Chemistry Research. 2002;41(22):5510-5515.

[193] Gross J. An equation-of-state contribution for polar components: Quadrupolar molecules. AIChE Journal. 2005; 51(9):2556-2568.

[194] Gross J, Vrabec J. An equation-of-state contribution for polar components: Dipolar molecules. AIChE Journal. $2006 ; 52(3): 1194-1204$.

[195] Vrabec J, Gross J. Vapor-liquid equilibria simulation and an equation of state contribution for dipole-quadrupole interactions. The Journal of Physical Chemistry B. 2008;112(1):51-60.

[196] Peng DY, Robinson DB. A new two-constant equation of state. Industrial \& Engineering Chemistry Fundamentals. 1976;15(1):59-64.

[197] Chapman WG, Jackson G, Gubbins KE. Phase equilibira of associating fluids. Chain molecules with multiple bonding sites. Molecular Physics. 1988;65:1057-1079.

[198] Chapman WG, Jackson G, Gubbins KE, Radosz M. New reference equation of state for associating liquids. Industrial \& Engineering Chemistry Research. 1990;29:1709.

[199] Yarrison M, Chapman WG. A systematic study of methanol+n-alkane vapor-liquid and liquid-liquid equilibria 
using the CK-SAFT and PC-SAFT equations of state. Fluid Phase Equilibria. 2004;226:195-205.

[200] Huang SH, Radosz M. Equation of state for small, large, polydisperse, and associating molecules. Industrial \& Engineering Chemistry Research. 1990;29(11):2284-2294.

[201] Lafitte T, Apostolakou A, Avendano C, Galindo A, Adjiman CS, Müller EA, Jackson G. Accurate statistical associating fluid theory for chain molecules formed from Mie segments. The Journal of Chemical Physics. 2013; $139(15): 154504$.

[202] Papaioannou V, Lafitte T, Avendano C, Adjiman CS, Jackson G, Müller EA, Galindo A. Group contribution methodology based on the statistical associating fluid theory for heteronuclear molecules formed from Mie segments. The Journal of Chemical Physics. 2014;140(5):054107.

[203] Gil-Villegas A, Galindo A, Whitehead PJ, Mills SJ, Jackson G, Burgess AN. Statistical associating fluid theory for chain molecules with attractive potentials of variable range. The Journal of Chemical Physics. 1997;106:4168.

[204] Galindo A, Davies LA, Gil-Villgeas A, Jackson G. The thermodynamics of mixtures and the corresponding mixing rules in the SAFT-VR approach for potentials of variable range. Molecular Physics. 1998;93(2):241-252.

[205] Blas FJ, Vega LF. Thermodynamic behaviour of homonuclear and heteronuclear Lennard-Jones chains with association sites from simulation and theory. Molecular Physics. 1997;92:135-150.

[206] Blas FJ, Vega LF. Prediction of binary and ternary diagrams using the statistical associating fluid theory (SAFT) equation of state. Industrial \& Engineering Chemistry Research. 1998;37(2):660-674.

[207] Soave G. Equilibrium constants from a modified Redlich-Kwong equation of state. Chemical Engineering Science. $1972 ; 27(6): 1197-1203$.

[208] Redlich O, Kwong JNS. On the thermodynamics of solutions. V. an equation of state. fugacities of gaseous solutions. Chemical Reviews. 1949;44(1):233-244.

[209] Dortmund data bank (accessed january 2020) [Www.ddbst.com]; 2020.

[210] Linstrom P, Mallard W. NIST Chemistry WebBook, NIST standard reference database number 69 [Website]; 2019. National Institute of Standards and Technology, Gaithersburg MD (retrieved january 2020). 


\section{Enrichment at Vapour-Liquid Interfaces of}

\section{Mixtures: Establishing a Link between \\ Nanoscopic and Macroscopic Properties}

Simon Stephan and Hans Hasse*

Laboratory of Engineering Thermodynamics (LTD), TU Kaiserslautern, Kaiserslautern 67663, Germany

*Hans.Hasse@mv.uni-kl.de

Friday $3^{\text {rd }}$ July, 2020 
This Supplementary Material of the publication Enrichment at Vapour-Liquid Interfaces of Mixtures: Establishing a Link between Nanoscopic and Macroscopic Properties contains the following points:

- Details on the digitalisation procedure

- Summary of the VLE data employed for empirical enrichment model

- Selection of isothermal $p-x$ phase diagrams of binary Lennard-Jones mixtures employed for the training-dataset 


\section{Details on the Digitalisation Procedure}

Since the vast majority of publications (cf. Table 1 in the main body of this work) report on density profiles $\rho_{i}(z)$ only graphically, the enrichment $E_{2}$ (cf. Eq. (1) in the main body of this work) had to be extracted from that data manually. Therefore, screenshots of the $\rho_{i}(z)$ plots were extracted from a given publication and required data for the computation of the enrichment $E_{2}$ was metered using the Web Plot Digitizer [94]. A database was established (see attached spread sheet file) based on that data.

Each data point $j$ consists of the following data obtained from a given publication reporting vapour-liquid interfacial density profiles (cf. Table 1) or databases [209]:

- The temperature $T_{j}$ and

- the liquid bulk phase mole fraction $x_{2, j}^{\prime}$ to specify the state point.

- The enrichment $E_{2, j}$ and the difference of the bulk densities $\Delta \rho_{2, j}$ measured from the density profile $\rho_{2, j}(z)$.

- The standard deviation from five repeated 'measurements' for all manually digitalised data.

- The partition coefficient $K_{2, j}^{5 \%}$ at $x_{2}^{\prime}=0.05 \mathrm{~mol} \mathrm{~mol}^{-1}$ at $T_{j}$ (either taken from the same publication reporting the density profiles or taken from the Dortmund Data Base [209] or NIST database [210]).

- The critical density $\rho_{\mathrm{c}, 1}$ of the high-boiling component 1 (also either taken from the same publication reporting the density profiles or taken from the Dortmund Data Base [209] or NIST database [210]).

To compute $E_{2, j}$ and $\Delta \rho_{2, j}$, the three points $\max \left(\rho_{2}(z)\right), \rho_{2}^{\prime}$, and $\rho_{2}^{\prime \prime}$ were measured from a given $\rho_{2}(z)$ plot. If the concentration of the low-boiling component in the liquid phase $x_{2, j}^{\prime}$ - to specify the state point - was not explicitly reported, it was computed from

$$
x_{2}^{\prime}=\frac{\rho_{2}^{\prime}}{\rho_{1}^{\prime}+\rho_{2}^{\prime}}
$$

which additionally required the measuring of the bulk phase density $\rho_{1}^{\prime}$. In some cases, neither the highboiling component density profile $\rho_{1}(z)$, nor the bulk phase composition was reported. In such cases, $x_{2, j}^{\prime}$ was taken from reported phase diagrams.

Each digitalisation was repeated five times; the actual value for each required property was taken from the mean value of the individual measurements and an uncertainty caused by the digitalisation was estimated from the standard deviation of the repeated values. The mean value of the absolute uncertainty was $\delta E_{2}= \pm 0.11$.

For some mixtures, the required VLE data was not available in databases - especially the model mixtures. In such cases, $x_{2}^{\prime \prime}$ at $x_{2}^{\prime}=0.05 \mathrm{~mol} \mathrm{~mol}^{-1}$ for the computation of $K_{2, j}^{5 \%}$ was also obtained by digitalisation from phase diagrams reported in respective publications. 
Challenges during the digitalisation:

Challenges emerged, when plots for density profiles were small, the resolution was low, and line width and symbol size were particularly large or hard to detect precisely. This became particularly a problem for density profiles at very low concentrations of the low-boiling component such that $\rho_{2}^{\prime}$ and $\rho_{2}^{\prime \prime}$ practically collapse with the abscissa of the respective plot. In such cases the value of $\rho_{2}^{\prime}$ and/ or $\rho_{2}^{\prime \prime}$ can get in the size of a pixel during the digitalisation. Since such state points often correspond to large enrichment, the digitalisation yields large uncertainties for such data - in both $E_{2}$ and $x_{2}^{\prime}$. Sometimes, the density profiles would also not be plotted to the exact bulk density values, i.e. the end of the density profiles would still posses a gradient $\mathrm{d} \rho_{i} / \mathrm{d} z \neq 0$.

\section{VLE Data Employed for the Enrichment Model}

For the training-dataset, all VLE data that is required for the empirical modelling could simply be taken from the publication in which the density profile was reported $[14,25,27]$. For the test-dataset, the required VLE data (see list above) was taken either from the publication that reported the density profiles or it was taken from the Dortmund Data Base [209] or NIST database [210]. In practically all of these cases, the partition coefficient was not exactly available at the prescribed $x_{2}^{\prime \prime}$ at $x_{2}^{\prime}=0.05 \mathrm{~mol} \mathrm{~mol}^{-1}$ and the given $T$. For the liquid phase composition, the vast majority of data points was available at $x_{2}^{\prime}=0.05 \pm 0.005 \mathrm{~mol} \mathrm{~mol}^{-1}$. For the temperature, most data points were available within $2 \%$ of the required temperature. Fig. S1 shows the histogram of the available VLE data for the considered systems (cf. Table 1 in the main body of the present work). The enrichment model was only applied, if the available VLE data did not deviate more than $10 \%$ from the temperatures the density profiles were reported for and data on the partition coefficient was available within $x_{2}^{\prime}=0.05 \pm 0.015 \mathrm{~mol} \mathrm{~mol}^{-1}$. This was the case for more than $99 \%$ of the data points of the entire database on enrichment data.
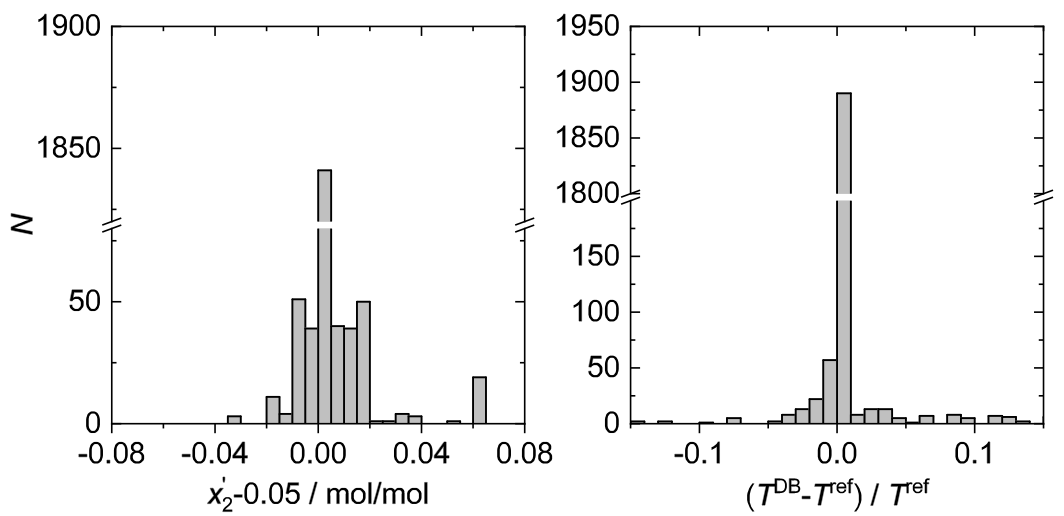

Figure S1. Histogram of the available VLE data for the prediction of the enrichment of the literature data. Left: Histogram for the absolute deviation of the prescribed liquid phase concentration. Right: Histogram of the relative deviation of the required temperature. 'DB' indicates the temperature of VLE data taken from databases as input for the enrichment model; 'ref' indicates the temperature of the reference data, cf. Table 1. 


\section{Phase Diagrams of Binary Lennard-Jones Mixtures of the Training-Dataset}

Fig. S2 shows a selection of the isothermal $p-x$ phase diagrams of the Lennard-Jones mixtures used in the training-dataset. They were calculated by the PeTS EOS, which is known to give an excellent representation of the vapour-liquid equilibrium of that particular Lennard-Jones fluid and its mixtures $[25,62,154]$. Representative results for 30 systems are shown in Fig. S2. For all mixtures the high-boiling component 1 is the same, while the low-boiling component 2 in the mixtures varies. The variation of the molecular interaction parameters yields a large variety of phase behaviours. For a detailed discussion see Refs. [14, 25]. 


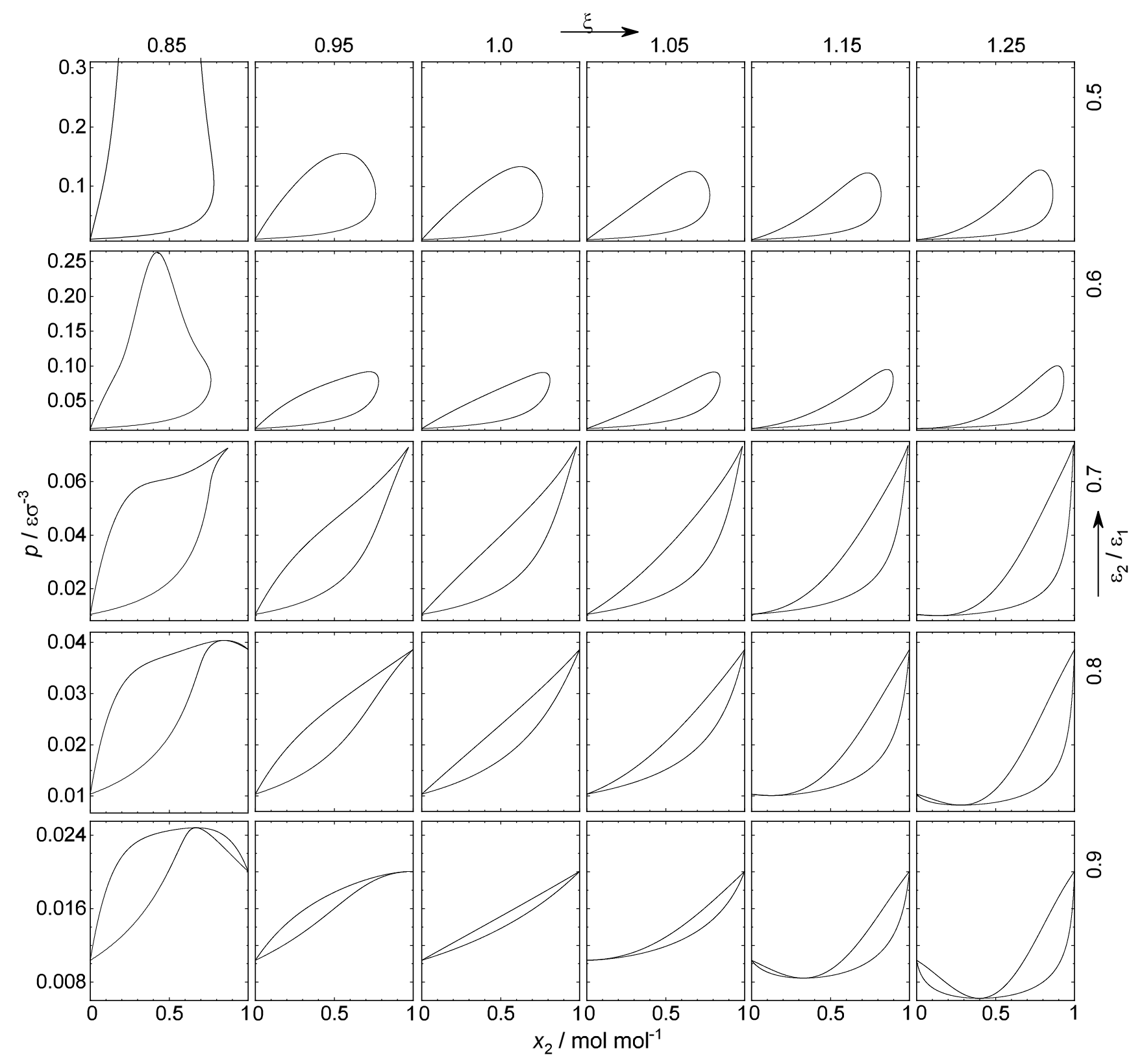

Figure S2. Selection of isothermal $p-x$ phase diagrams of binary Lennard-Jones mixtures at $T=0.77 \varepsilon k_{\mathrm{B}}^{-1}$ for different binary interaction parameter $\xi$ and ratios of the dispersion energies of both components $\varepsilon_{2} / \varepsilon_{1}$ obtained from the PeTS EOS [25, 154]. 